\title{
22. HIGH-RESOLUTION LITHOLOGIC CHARACTERIZATION OF SEQUENCES ON THE NEW JERSEY MARGIN SLOPE THROUGH INVERSION OF LEG 150 LOGGING DATA FOR LITHOLOGIES ${ }^{1}$
}

\author{
Bryce W. Hoppie ${ }^{2}$
}

\begin{abstract}
Research presented herein shows the derivation of a uniquely determined linear inversion model of downhole logging data that accurately predicts lithologies through most Leg 150 logged intervals. Five lithologic end-members, consisting of terrigenous (quartz, albite, and microcline), opaline (opal-A and opal-CT), calcareous (aragonite and calcite), argillaceous (all clay and mica minerals), and "heavies" (siderite and pyrite) compositions, were modeled. Modeling results abide by theoretical constraints, match semiquantitative X-ray diffraction analyses to within $10 \%$, and closely approximate sedimentologist's descriptions of recovered cores. Modeling results complete the lithologic characterization of the sediments drilled during Leg 150 by providing compositional estimates for intervals with incomplete core recovery, as well as additional high-resolution $(0.33 \mathrm{~m})$ petrologic estimates and insight to subtle lithologic variations not readily apparent to sedimentological observation.

Modeling results show important stratigraphic information regarding the lithologic nature of sequences on the New Jersey slope. For example, modeling results highlight dissimilar lithologic compositions among coeval sediments from different midslope sites as well as the presence of lithologic cycles within previously defined sequences. Results indicate the upper and middle slope is a dynamic system with heterogeneous deposition and differential erosion. Integration of available biostratigraphic data indicates these processes may be influenced by forces operating on frequencies correlative to glacioeustatic forces as far back as the middle Eocene.
\end{abstract}

\section{INTRODUCTION}

Five sites on the North American continental slope and rise were cored and logged during Ocean Drilling Program (ODP) Leg 150, the New Jersey Margin continental slope and rise. The sites range from 150 to $220 \mathrm{~km}$ east-southeast of Atlantic City, New Jersey (Fig. 1). Total drilling depths range between 700 and 1200 meters below seafloor (mbsf). Overall excellent core recovery $(87.9 \%$ for all holes) was obtained from both Eocene hemipelagic carbonate rocks and Oligocene to Holocene siliciclastic sediments except for cores containing suspected sequence boundaries (e.g., $79.8 \%$ core recovery in cores containing sequence boundaries for Site 902 , and $69.3 \%$ for Site 903).

Leg 150 constitutes part of the proposed Mid-Atlantic Transect (MAT; cf. Mountain et al., 1992), an integrated off- and onshore drilling project designed to characterize the nature and timing of deposition along a passive margin dominated by siliciclastic deposition during intervals of changing relative sea level. The major goals of Leg 150 included dating Oligocene to Holocene unconformities, acquiring data for modeling the amplitude and rate of sea-level changes, and documenting facies variations associated with sea-level oscillations (Mountain et al., 1993).

The purpose of this study is to provide additional information on the lithologic composition of stratigraphic horizons penetrated during Leg 150 drilling operations. It uses a numerical modeling method, known as downhole log inversion, to provide (1) compositional information for stratigraphic intervals with missed core recovery, (2) high-resolution compositional estimates free of significant sampling bias, and (3) a tool for analyzing compositional trends on a regional scale by using previously logged holes on shelf and slope. This information will improve both the vertical and areal characterization of

'Mountain, G.S., Miller, K.G., Blum, P., Poag, C.W., and Twichell, D.C. (Eds.), 1996. Proc. ODP, Sci. Results, 150: College Station, TX (Ocean Drilling Program).

${ }^{2}$ Earth Science Department, University of California, Santa Cruz, Santa Cruz, CA 95064, U.S.A. bwhoppie@ cats.ucsc.edu middle Eocene through Holocene horizons targeted by Leg 150, and assist in understanding of relationships between relative sea-level change and sequence architecture on passive margins dominated by siliciclastic sedimentation.

This paper covers all aspects of the numerical modeling of Leg 150 data for compositional information. First, I derive a variant of generally applied inversion models for improved modeling efficiency and accuracy. Next, the many steps needed to create accurate and meaningful downhole log, conventional core, and lithologic input data are thoroughly covered. The modeling method is then applied to all Leg 150 log data; results are checked for accuracy and discussed in the context of Leg 150 goals.

\section{LITHOLOGIC MODELING BY LOG INVERSION}

Excellent descriptions of general inversion techniques are provided by Doveton (1986) and Harvey et al. (1990). It is not the objective of this paper to derive another inverse model; however, as the inversion model used herein is considerably different from those cited in the above references, a short digression into the history and principles of log inversion techniques is necessary.

Savre (1963) introduced the method of inverting downhole log data for compositional information over $30 \mathrm{yr}$ ago. Briefly, the method operates by recognizing that any given downhole log response is the sum of the products of individual lithologic and fluid components and their respective individual $\log$ responses. Note that log responses are implicitly assumed to vary linearly with variations in component concentrations. For example, a typical downhole log response equation is

$$
\phi \mathrm{RHO}_{f}+\sum_{\mathrm{i}=1}^{n} \mathrm{p}_{i} \mathrm{RHO}_{i}=\mathrm{RHO}_{b}
$$

where $\phi=$ porosity, $\mathrm{RHO}_{f}=\log$ fluid density, $\mathrm{p}_{i}=$ percent rock volume of lithologic component $i, \mathrm{RHO}_{i}=\log$ density of lithologic component $i$, and $\mathrm{RHO}_{b}=$ total bulk density log response. 
Figure 1. Location map of drilling sites on the New Jersey shelf, slope, and rise. Sites drilled during Leg 150 are represented by solid circles and are labeled. Open circles represent oil exploration, USGS, and DSDP drill sites and core holes. Modified from Mountain et al. (1993) and Greenlee and Moore (1988).

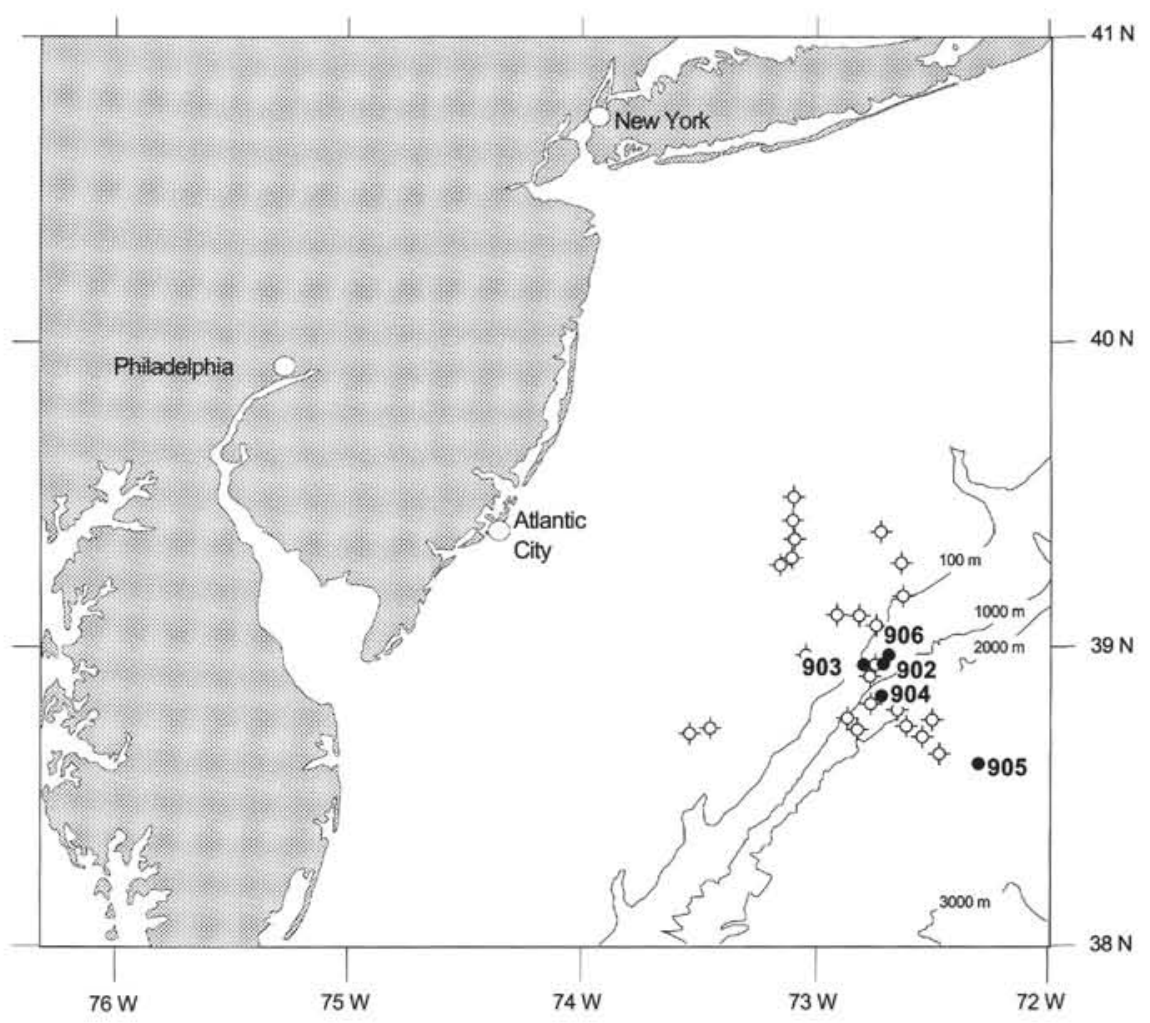

A second type of inverse system, called an underdetermined system, has more than one fewer log responses than components in the system. Such systems are solved by statistical methods that estimate the most-likely compositional combinations that could account for the overall log responses. Results from this type of model tend to have equitable proportions of components as this lessens the amount of error in the proportional estimate of any one component (Doveton, 1986). As Doveton (1986) explains, underdetermined models poorly model compositional characteristics of complex sedimentary units because sedimentary processes have no tendency toward mixing their constituent minerals in equitable proportions.

A third type of inverse model is called an overdetermined system. These models are applicable where the number of available log responses equals or outnumbers the number of components. This situation was quite rare prior to the late 1980 s; seldom were formations consisting of fewer than three or four components encountered. By the mid-1980s, however, advances in downhole logging tools (specifically, the development of the Geochemical Logging Tool [GLT]) made the available number of log responses increase dramatically. It is now common for modern logging operations to produce 10 or more $\log$ responses, thus allowing more uses of overdetermined systems (cf. Fisher et al., 1992; Hertzog et al., 1989; Wendlandt and Bhuyan, 1990). Overdetermined systems are solved by least-squares error minimization procedures and allow for more error analyses than underdetermined or uniquely determined inversion models (Doveton, 1986; Harvey et al., 1990; Quirein et al., 1986).

\section{Pitfalls of Inversion Models}

Given the lithologic complexity of most siliciclastic sedimentary successions, it is unlikely that any inversion model can accurately estimate the fractions of all their mineralogical components. Therefore, a more pragmatic approach is to model the succession in terms of a limited number of components or end-members that accurately approximate the lithology of the succession in question. Although these end-members may be mineralogically complex, they are assumed to have constant composition and log response characteristics through the intervals of interest.

in abbreviated matrix notation. 
While this approximation makes the practice of inverting downhole $\log$ data to estimate lithologic composition tractable, it adds three additional complications. First, although this simplification reduces the number of unknowns, it requires the number of components to be optimized. Modeling a system with too few components may ease the burden of estimating log response parameters, but it also masks meaningful lithologic information. Second, the proper log responses to these composite mineralogical end-members must be known with a high degree of accuracy. This point is especially important because even small variations in these estimates can cause drastic changes in end-member proportions (Doveton, 1986; Fisher et al., 1992). Finally, the log response of each end-member must be unique. In order for a lithotype end-member to be properly quantified, a linear relationship between one of its physical or compositional properties and a log response must exist. If this condition is not met, the downhole log response equations listed previously will not hold true, and the compositional estimates will be rendered invalid. In such cases, compositional estimates may obey all other constraints but are nevertheless meaningless.

\section{An Inversion Model for Leg 150}

This work uses a uniquely determined system (i.e., the number of downhole logs plus one equals the number of unknown lithotype endmembers) for two reasons: (1) underdetermined systems were excluded because they do not provide realistic compositional estimates in complex systems, and (2) a model using an overdetermined system would probably not be applicable to preexisting holes on the New Jersey Margin. Although it is not known with certainty, it is unlikely that the preexisting holes (see Fig. 1), which were drilled before 1985 (Mattick and Libby-French, 1988), possess the GLT or other advanced well logs. Therefore, it is unlikely that excess log responses, necessary for generating an overdetermined set of equations, exist for those holes. Thus, I elected to use an exactly determined system: one that would be applicable on a regional scale and that provides compositional estimates in lithologically complex sedimentary units.

The inversion model described below is a variant of the uniquely determined system. Additional time and effort are necessary in the acquisition of high-resolution, accurate core-measured physical properties. The model repays these additional expenses by providing improved accuracy while decreasing the amount of time spent searching for appropriate model lithologies and log response parameters. Again, the fundamental linear downhole log response equations are

$$
\begin{aligned}
& 1=\phi+\mathrm{p}_{1}+\mathrm{p}_{2}+\ldots \\
& \mathrm{c}_{1}=\phi \mathrm{X}_{1 f}+\mathrm{p}_{1} \mathrm{X}_{11}+\mathrm{p}_{2} \mathrm{X}_{12}+\ldots \\
& \mathrm{c}_{2}=\phi \mathrm{X}_{2 \mathrm{f}}+\mathrm{p}_{1} \mathrm{X}_{21}+\mathrm{p}_{2} \mathrm{X}_{22}+\ldots \\
& \ldots
\end{aligned}
$$

Given that the aforementioned complications are adequately mitigated, these equations can be solved explicitly. Practically however, the exact log response parameter of each end-member $\left(\mathrm{X}_{i j}\right)$ cannot be determined and results routinely fail to be physically reasonable. That is, the sum of the lithologic components $\left(\mathrm{p}_{i}\right)$ is either less than zero or greater than unity.

The potentially tedious task of determining the correct log response parameters $\left(\mathrm{X}_{i j}\right)$ is partially alleviated by defining additional constraint equations. This is done by solving equations (1) for downhole $\log$ porosity $\left(\phi_{l o g}\right)$ and conventional core porosity $\left(\phi_{\text {core }}\right)$. The first such equation is

$$
1-\phi_{\log }=\mathrm{A}_{0}\left(\mathrm{c}_{1}-\mathrm{X}_{1 f}\right)+\mathrm{B}_{0}\left(\mathrm{c}_{2}-\mathrm{X}_{2 f}\right)+\ldots
$$

$A_{0}, B_{0}$, etc., are explicit functions of the end-member and fluid $\log$ responses. (Also note that this relationship assumes that the fluid $\log$ responses $\left[\mathrm{X}_{i f}\right]$ are known.) Specifically, the functions $\mathrm{A}_{0}, \mathrm{~B}_{0}$, etc. (written for a two-component system) are

$$
A_{0}=\left(X_{22}-X_{21}\right) /\left[\left(X_{11}-X_{1 f}\right)\left(X_{22}-X_{2 f}\right)-\left(X_{12}\right)\left(X_{21}-X_{2 f}\right)\right]
$$

and

$$
\mathrm{B}_{0}=\left(\mathrm{X}_{11}-\mathrm{X}_{12}\right) /\left[\left(\mathrm{X}_{11}-\mathrm{X}_{1 f}\right)\left(\mathrm{X}_{22}-\mathrm{X}_{2 f}\right)-\left(\mathrm{X}_{12}\right)\left(\mathrm{X}_{21}-\mathrm{X}_{2 f}\right)\right]
$$

If high-resolution core porosities are available and are (1) rebound corrected, (2) depth-matched to the log data, and (3) averaged similarly to log data, they should closely approximate downhole log porosities. Then, Equation 2 may be rewritten in terms of core porosities, that is,

$$
1-\phi_{\text {core }}=\mathrm{a}_{0}\left(\mathrm{c}_{1}-\mathrm{X}_{1 f}\right)+\mathrm{b}_{0}\left(\mathrm{c}_{2}-\mathrm{X}_{2 f}\right)+\ldots
$$

Note that consistency between log and core porosity allows explicit functions $A_{0}, B_{0}$, etc., to be replaced by regression coefficients $\mathrm{a}_{0}$, $\mathrm{b}_{0}$, etc., formed by the linear regression of total downhole log response against core porosity data. If there is good correlation between total $\log$ responses and core porosity, then $\mathrm{a}_{0}, \mathrm{~b}_{0}$, etc., form a bridge by which individual log responses can be constrained. That is, the sum of the products of $\mathrm{a}_{0}, \mathrm{~b}_{0}$, etc., and the individual downhole log responses of any one particular tool (i.e., $X_{11}, X_{21}$, etc.) may be set equal to unity and rearranged to solve for the individual downhole log responses. Expressed numerically, these constraints are

$$
\begin{aligned}
& 1=a_{0}\left(X_{11}-X_{1 f}\right)+b_{0}\left(X_{21}-X_{2 f}\right)+\ldots \\
& 1=a_{0}\left(X_{12}-X_{1 f}\right)+b_{0}\left(X_{22}-X_{2 f}\right)+\ldots \\
& \ldots
\end{aligned}
$$

Thus, the incorporation of core data allows the derivation of Equations $5 \mathrm{~A}$ and $5 \mathrm{~B}$, which directly provide $\mathrm{n}$ component log responses in a system with $n^{2}$ unknown component log responses; $n^{2}$ $n$ log responses must be estimated by independent means. Consequently, the problem of determining accurate log responses is only partially alleviated. The additional constraints, however, present a significant improvement in choosing input parameters for inversion modeling. This process not only lessens the number of estimated parameters needed but also, if Equations $5 \mathrm{~A}$ and $5 \mathrm{~B}$ are used specifically to estimate a known compositional or physical property, the equations serve as a check on other physical or compositional properties which are less well defined.

After appropriate log response parameters are determined, the process of calculating component fractions reverts to the methods of uniquely determined systems outlined in Doveton (1986) and Harvey et al. (1990).

\section{MODELING INPUT DATA}

As shown above, the ease and accuracy of this uniquely determined inversion model can be dramatically improved with the incorporation of core data. This section discusses the acquisition and manipulation of Leg 150 shipboard and shore-based core data as well as $\log$ and $\log$ parameter data needed for the inversion model.

\section{Core Porosity Data}

All core porosities were measured by the gravimetric method (Mountain, Miller, Blum, et al., 1994, see "Explanatory Notes" chapter). Shipboard gravimetric porosity measurements were made on the average of 1 per every $3 \mathrm{~m}$ on all holes with downhole logs. Clearly, this sampling interval is inadequate for the detailed log-core porosity 
match needed for this work. Shipboard data were therefore augmented by 297 post-cruise samples taken from selected intervals of wellpreserved cores.

Post-cruise samples were taken from key lithologic units (discussed below) corresponding to intervals with good logging data (uniform, gauge holes with minimal DRHO log corrections). The average sampling interval of the post-cruise samples was $0.33 \mathrm{~m}$. This interval roughly approximates the averaged sampling interval of the downhole density and porosity logs. Post-cruise gravimetric analyses were made on a Quantichrome Pentapycnometer at the ODP laboratories in College Station, TX. This apparatus is identical to that used onboard the Resolution and was used specifically to replicate shipboard porosity data as closely as possible.

There was concern prior to the post-cruise sampling that the shipboard core porosities would not be replicated due to the drying of the cores during shipping and storage. This problem was addressed by choosing one out of every 20 samples from a position immediately adjacent to a shipboard sample to serve as a check on the consistency of the core porosity data. Various lithologies (e.g., sandstone, siliceous and calcareous mudstone, claystone, etc.) were included in this check. As shown in Figure 2, no significant difference was found between shipboard and post-cruise porosity measurements. Shipboard and post-cruise porosity data were therefore combined into one core porosity data set.

Core porosities were checked for rebound affects. Several tests were made, including comparison of log and core bulk densities and porosities, individual lithology vs. depth plots similar to Fisher et al. (1992), and correlation to compactional porosity trends identified by Hamilton (1971). Each analysis is described in greater detail below.

Several steps were required for direct comparison of log and core porosity data. First, gravimetric core data were depth-corrected according to the corrections recommended by Hoppie (chapter 29, this volume). Gravimetric and corrected Gamma-ray Attenuation Porosity Evaluator (GRAPE) core bulk density data were then compared to ensure the GRAPE data, which span greater intervals of core and are of higher resolution, could serve as a proxy for the gravimetric data. After this condition was assured, GRAPE and log bulk densities were

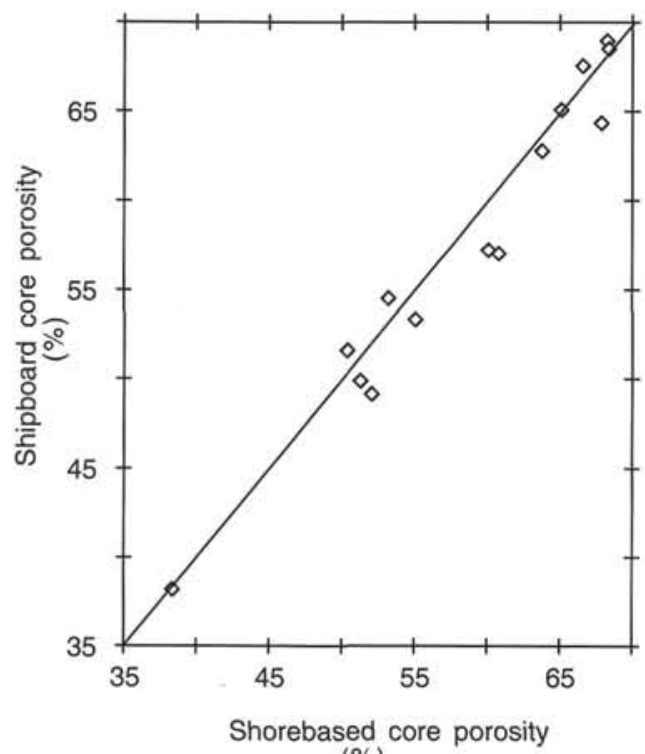

(\%)

Figure 2. Cross plot of shipboard and shore-based core porosities. Both data sets were acquired by gravimetric analyses on Quantichrome Pentapycnometers. Cross plot shows no trend or significant difference between the two data sets. plotted on a common depth axis. From these plots several correlation points were chosen from which a linear depth transform function was devised to align the core and log depth records. An example of the raw and depth-adjusted core and log data is shown in Figure 3. Finally, an interpolative curve was fit to the log porosity data and resampled at the corrected depths of the gravimetric porosity data. The two independent measures of porosity are not exactly the same because the log data averaged over approximately $0.33 \mathrm{~m}$; however, over the broad scale at which this survey attempts to compare the two records, the measures should be approximately equal. Depth and cross plots of the core and log porosity data (limited to sections with approximately 11 in. [27.94 cm] diameter holes, and low DRHO corrections) are shown in Figure 4. Cross plots indicate that core porosities may require from $0 \%$ to $9 \%$ (average $=2 \%$ ) correction to match in situ log measured porosities. This fit, however, is not consistent among the four holes studied (see Fig. 4), and should be considered questionable. Therefore, this first check of compactional trends is equivocal, but does indicate that porosity corrections, if necessary, are small.

The aforementioned procedure was repeated with the population of porosity data separated by individual lithologies. Information for categorizing the core porosity data by lithology was taken from the shipboard sedimentologists' lithostratigraphic records (Mountain, Miller, Blum, et al., 1994, see individual site chapters). Lithologies were categorized as sand/siltstone, calcareous mudstone, chalk, porcelanous chalk, claystone, and biosiliceous mudstone. Resulting cross plots (Fig. 5) indicate that chalks require compactional correction.

This analysis highlights an inconsistency in core and downhole porosity measurements in biosiliceous mudstones. I speculate that the observed differences in core and log porosities (see Fig. 5) may arise from the gravimetric method of core porosity analysis. Gravimetric samples are heated to determine the wet and dry sample weights. This
A

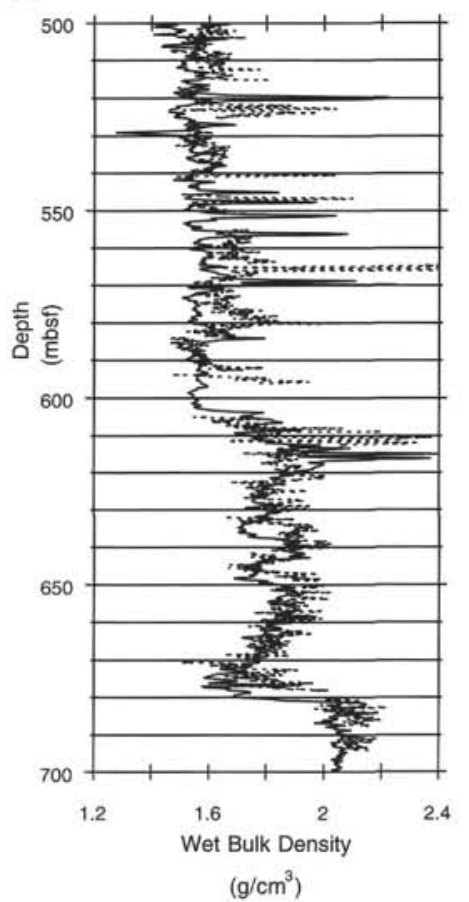

B

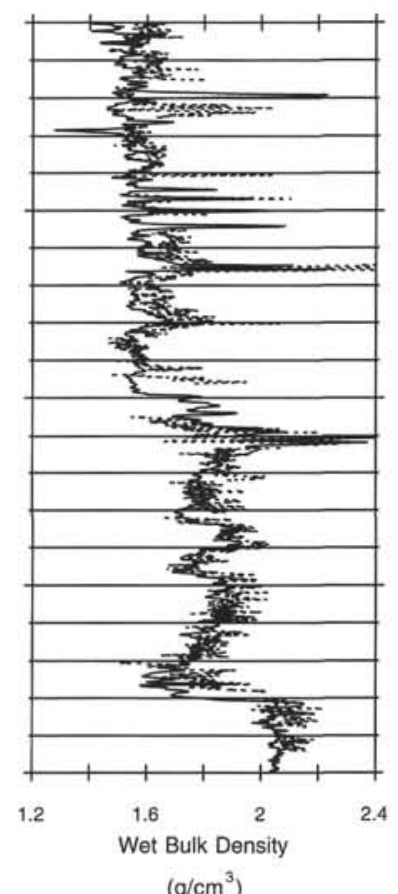

Figure 3. Pre- and post-depth-corrected core (A and B, respectively) and log wet bulk density for Hole 902D. Solid and dashed lines represent downhole and GRAPE density data, respectively. Plots are shown as examples of how depth-shifting improves core-log correlation. Depth shifting was necessary prior to any core-log inversion modeling; similar depth shifts were performed on Holes 904A and 906A. 


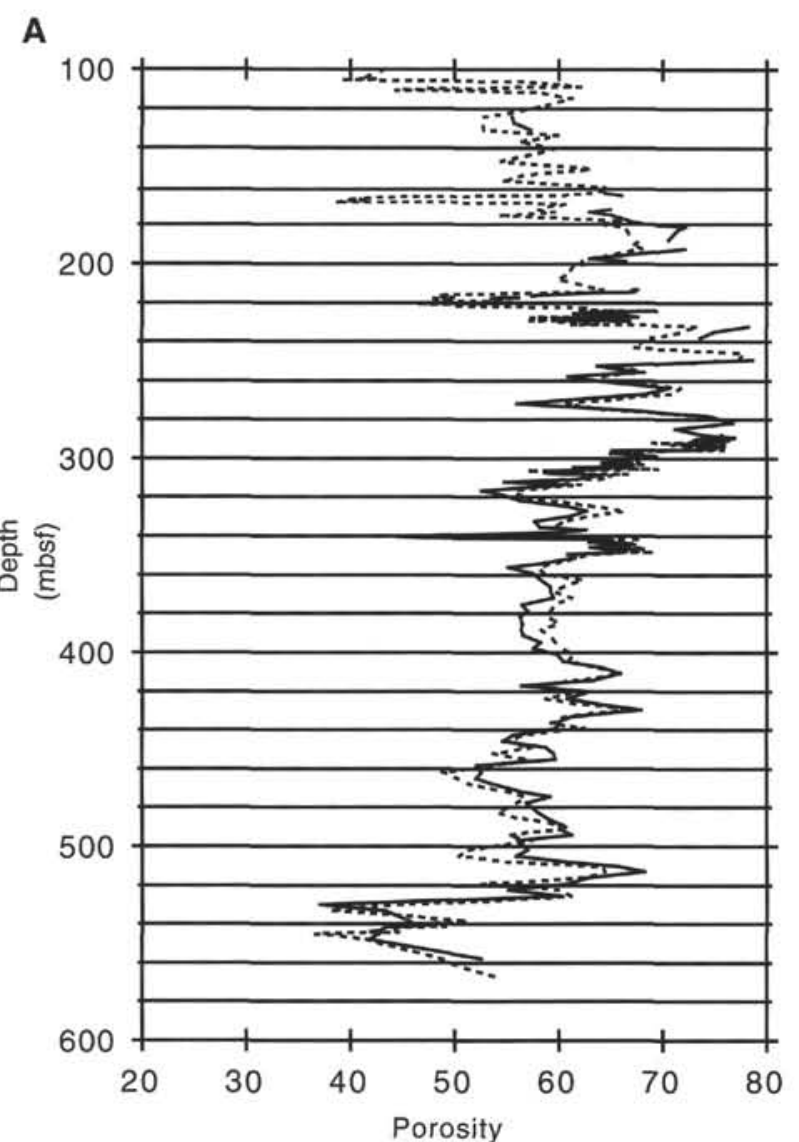

(\%)

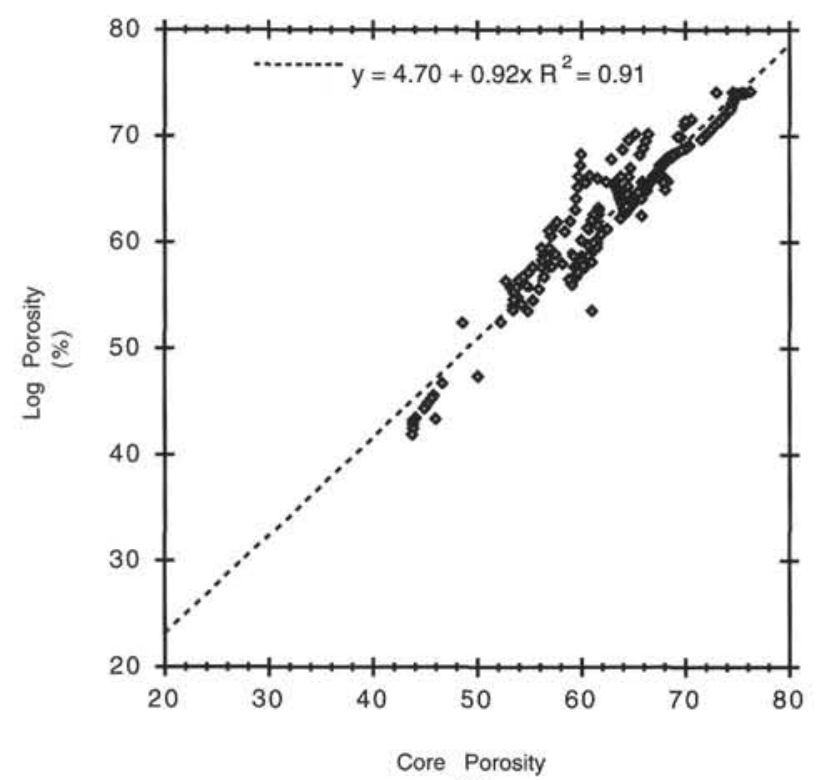

(\%)

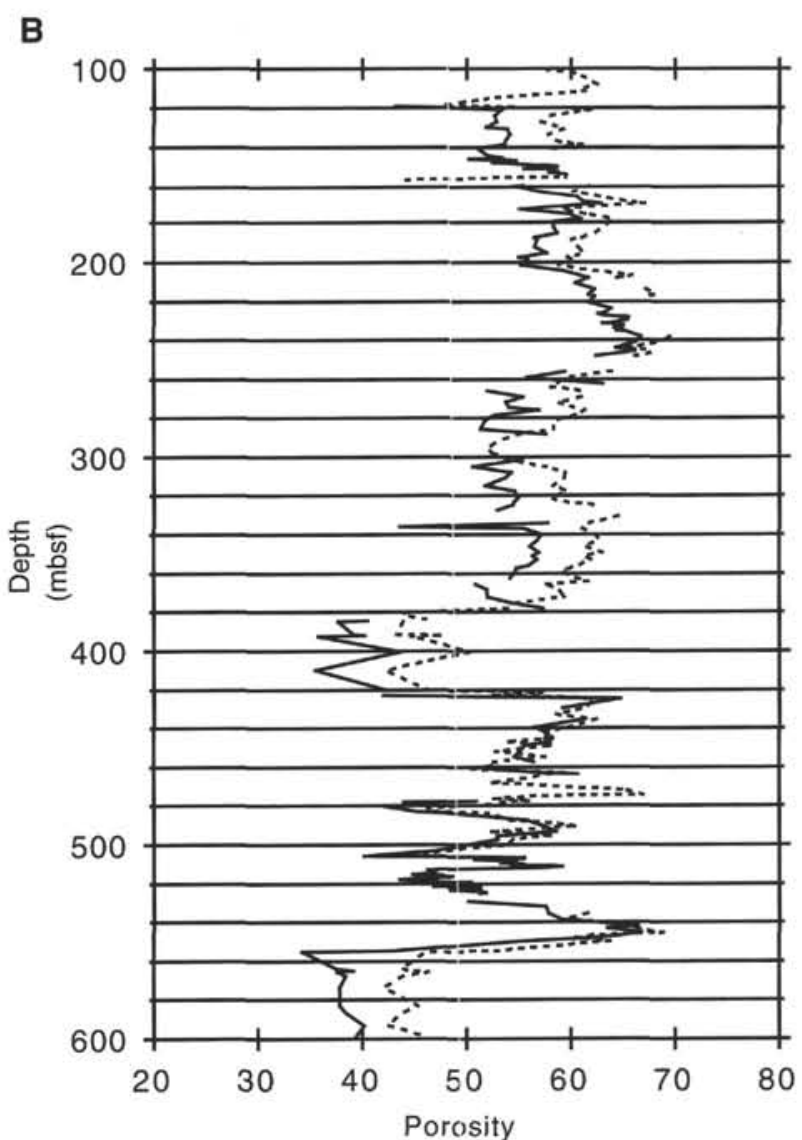

$(\%)$

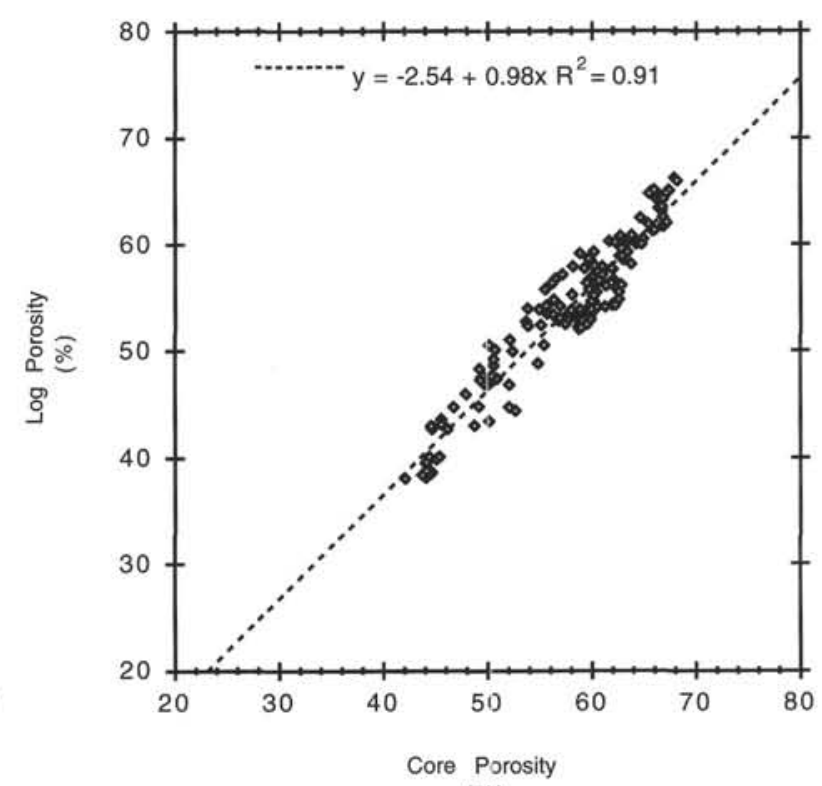

$(\%)$

Figure 4. Depth and cross plots of core and log porosity data. Divergence from slopes of 1 and intercepts of 0 are caused by core rebound, small misfits of core and $\log$ data, and inaccurate $\log$ porosity estimates due to environmental conditions. A. Hole 904A. B. Hole 906A. Assuming depth matching was performed perfectly and all log data were properly corrected and/or edited, these plots show that only minor overall rebound corrections are necessary for the core data used in log inversion modeling. 
process may cause not only inter- and intraparticle pore-filling fluids to evaporate but may also release and vaporize some of the water bound in the solid-phase amorphous silica of the diatom frustules in the mudstone. The end result is that core porosities of biosiliceous mudstones are greater than log measured porosities. The effect on this study, however, is relatively insignificant because the discrepancy between core and log porosities caused by the generally low concentration (< 10\% on average; Mountain, Miller, Blum, et al., 1994, see individual site chapters) of diatom frustules in the sediments is small.

Compactional trends of individual lithologies were also studied without comparison to downhole logs in a manner consistent with Fisher et al. (1992). Porosities corresponding to each lithology were plotted vs. depth and compactional trends were observed (Fig. 6). This exercise showed that only chalk and, to a much lesser degree, calcareous mudstone and claystone lithologies show compactional effects with depth (Fig. 7). A depth-dependent function for the correction of chalk data was derived (see Fig. 7) and found to approximate closely the correctional function described by Hamilton (1971). All other lithologies exhibited no consistent porosity changes with depth.

In summary, these procedures indicate that only chalk lithologies require appreciable rebound corrections prior to the integration of core porosity data into the lithology inversion model. A small misfit may also be expected in biosiliceous mudstones but it must be accepted as an inherent uncertainty of the model because the core to log discrepancy cannot be readily corrected. Integration of all other porosity data can be done without rebound correction.

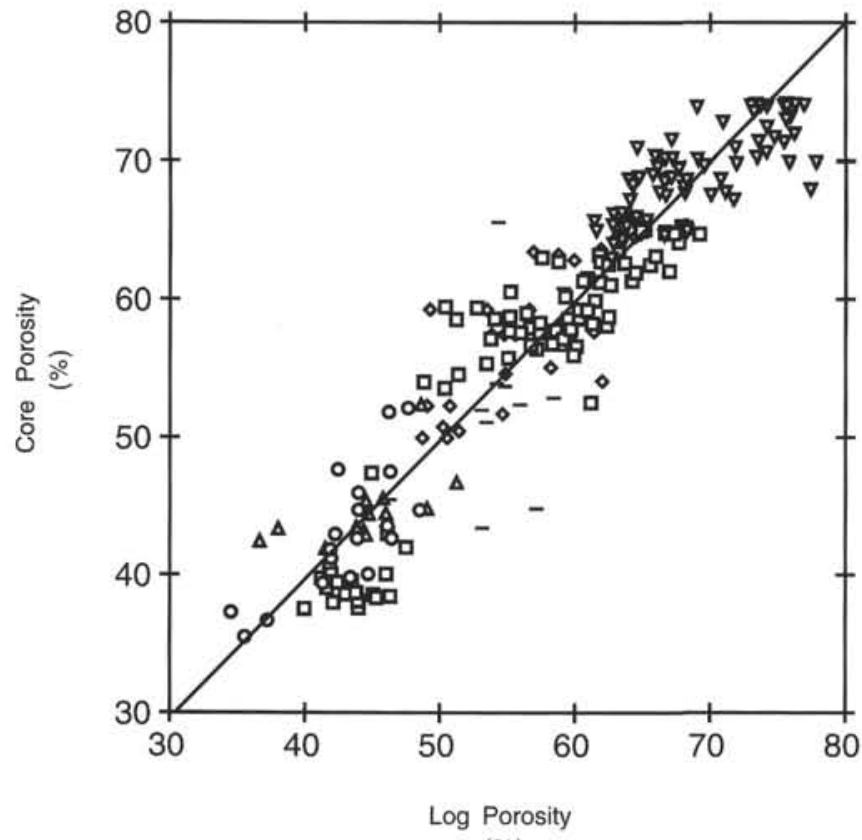

(\%)

Figure 5. Cross plot of all core and log porosity data from all logged holes (except Hole 905A) plotted as a function of lithology. Acquisition of core and $\log$ porosity data is covered in the text. Lithologic information was obtained from the site reports of Leg 150 (Mountain, Miller, Blum, et al., 1994, see individual site chapters). Symbols are as follows: circles = sandstones, triangles $=$ porcellanous chalks, diamonds $=$ calcareous mudstones, dashes $=$ claystones, squares $=$ chalks, and inverted triangles $=$ biosiliceous mudstones. Divergence from slopes of 1 and intercepts other than 0 are caused by porosity rebound. Only chalk lithologies show a need for rebound correction.

\section{Model Lithologies}

The selection of end-member lithologies were broadly limited by compositional and textural observations made by shipboard sedimentologists on recovered cores. Sedimentologists' records described six main compositional/textural lithotypes: sandstone, siltstone, claystone, chalk, and porcelanous chalk as well as several abundant accessory minerals including glauconite, siderite, and pyrite. Many hybrids, mixing various proportions of these main lithotypes, were noted in the shipboard sedimentologists' lithostratigraphic records at each site.

Shipboard and subsequent X-ray diffraction (XRD) analyses amplify these broad core descriptions and highlight the mineralogical complexity of the sediments recovered during Leg 150 . Table 1 lists observed minerals, location of their main occurrence, and the source of their identification.

The 18 different minerals listed, while certainly unique in a mineralogical sense, may be grouped into sets with common physical and compositional characteristics. Furthermore, many of the minerals can be grouped so as to retain valuable sedimentological and stratigraphic information. The key is therefore to recognize the physical and compositional properties of meaningful sedimentological end-members using combinations of minerals identified by XRD.

For example, sand/siltstones are of critical stratigraphic information to slope depositional environments of Leg 150 because they may be primary indicators of basinward shifts of facies and, thus, of sequence boundaries (cf. Van Wagoner et al., 1988). XRD identifies three mineralogical components that can be attributed mostly to sand/ siltstones: detrital quartz, albite, and microcline. These three minerals also possess similar physical properties and thus constitute an excellent end-member combination-one that has common physical char-

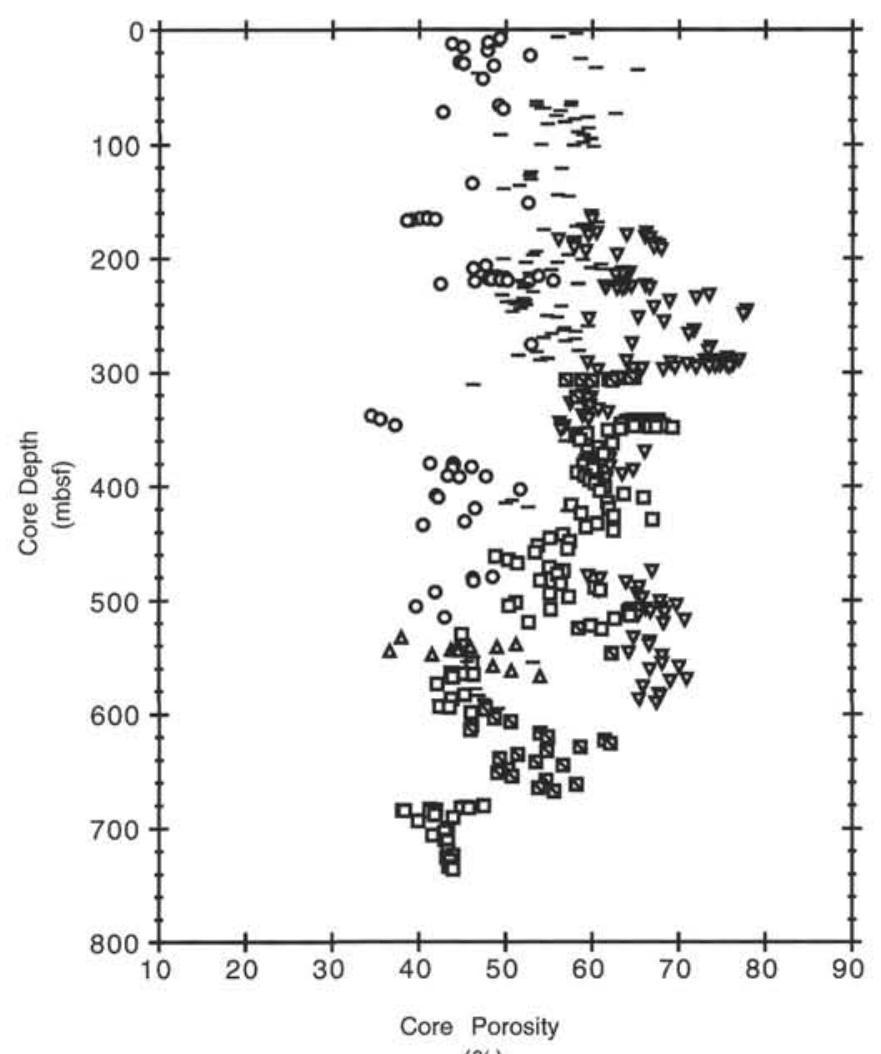

$(\%)$

Figure 6. Depth plot of all porosity data by lithology. Symbols are the same as those in Figure 5. Note inconsistent compaction trends in all lithologies except chalks, calcareous mudstones, and clays. 
A

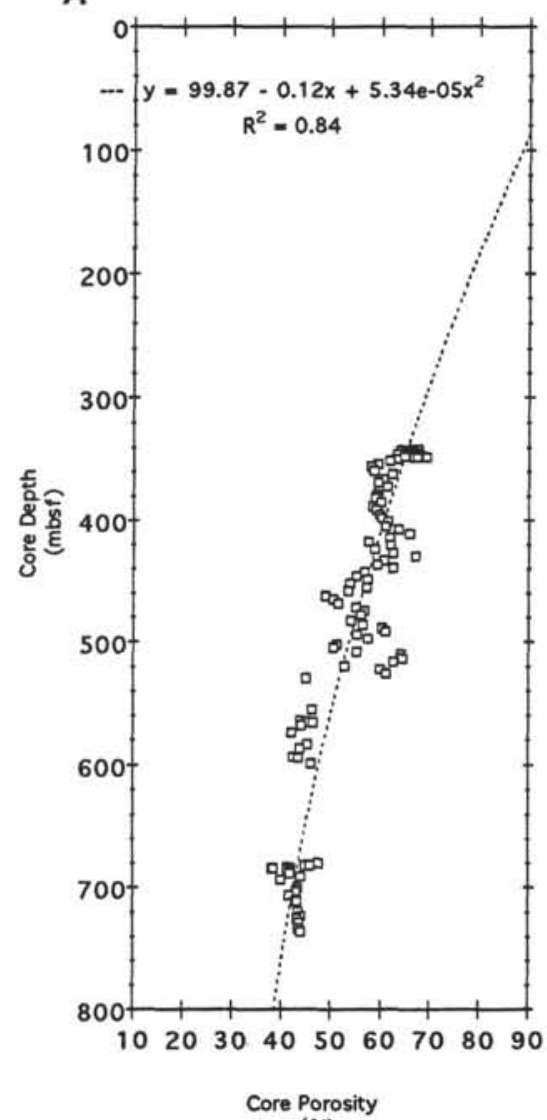

(\%)
B

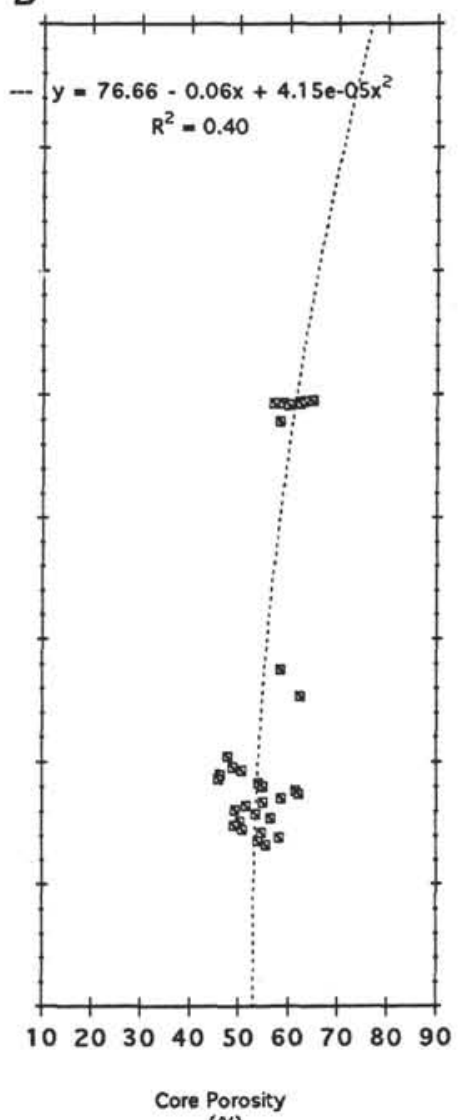

(\%)
C

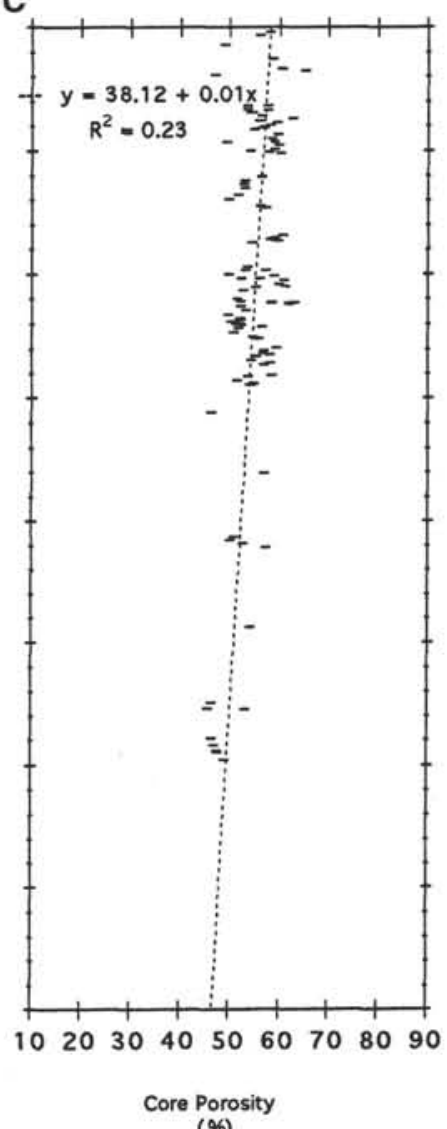

(\%)

Figure 7. Depth plots of porosity data from specific lithologies: (A) chalk, (B) calcareous mudstone, and (C) claystones. Best-fit curves in (A) and (B) are by second-order polynomial; the best-fit curve in (C) was by linear regression.

acteristics and yields valuable sedimentological information. Other end-members were chosen with a similar philosophy and include the following:

Opaline sediments: Sediments composed of mostly opal-A and/or opal-CT. These sediments have low grain density and high neutron porosity and photoelectric cross sections in common. The combination is also a good indicator, when found in abundance, of high planktonic productivity. Therefore, it marks intervals dominated by pelagic or hemipelagic sedimentation.

Calcareous sediments: Sediments composed of calcite, aragonite, and high and low magnesium calcite. This end-member has moderate grain densities, low neutron porosity, and high photoelectric crosssectional areas. Like the opaline sediments, they are good indicators of the dominance of pelagic sediment sources although their concentration may be altered by diagenesis.

Clay-rich (argillaceous) sediments: Sediments composed of smectite, illite, glauconite, kaolinite, muscovite, and mixed-layer clays. Although clay mineral physical properties may vary dramatically, the predominance of illite and kaolinite in this group allows for good average physical parameters to be estimated. The clay-rich sediments have intermediate grain densities, high neutron porosities, and intermediate photoelectric cross sections. The proportions of clays in sediments carries many important stratigraphic and oceanographic implications because they generally require a terrestrial source and low depositional energies.

"Heavy minerals" end-member: Sediments with siderite and pyrite. Although this carbonate and sulfide are mineralogically dissimilar, their common high grain densities and extremely high photo-
Table 1. Summary of all minerals identified in cores recovered during Leg 150 by X-ray diffraction analyses.

\begin{tabular}{|c|c|c|}
\hline Mineral & Mineral occurrences & References \\
\hline Albite & Pervasive & $1,2,3$ \\
\hline Amphibole & $903: 50-350 \mathrm{mbsf}$ & 1,2 \\
\hline Aragonite & Overall extent poorly defined by XRD & 3 \\
\hline $\begin{array}{l}\text { Calcite (including high } \\
\text { and low } \mathrm{Mg} \text { ) }\end{array}$ & $\begin{array}{l}902: 500-750 \text { mbsf: } 903: 0-350, \text { mbsf, } \\
800-1000 \text { mbsf; } 904: 250-550 \text { mbsf }\end{array}$ & 1,3 \\
\hline Chlorite & $903:<350 \mathrm{mbsf} ; 905: 0-400 \mathrm{mbsf}$ & 2 \\
\hline Solomite & 902: 10-90 mbsf; $903: 0-300$ mbsf & $i$ \\
\hline Glauconite & Overall extent poorly defined by XRD & 3 \\
\hline Illite & Pervasive & 2,3 \\
\hline Illite-smectite & $\begin{array}{l}\text { 903: 750-1150 mbsf; } 904: 0-540 \mathrm{mbsf} \text {; } \\
\text { 905: 200-900 mbsf }\end{array}$ & 2,3 \\
\hline Kaolinite & Pervasive & 2,3 \\
\hline Microcline & Pervasive & $1,2,3$ \\
\hline Muscovite & Overall extent poorly defined by XRD & \\
\hline Opal-A & $\begin{array}{l}\text { 902: } 0-550 \text { mbsf; } 903: 0-900 \text { mbsf, } 904: \\
0-100 \text { mbsf; } 905: 0-550 \text { mbsf }\end{array}$ & 1,3 \\
\hline Opal-CT & $\begin{array}{l}\text { 902: } 550-750 \mathrm{mbsf} ; 903: 900-1150 \mathrm{mbsf}, \\
\text { 904: } 500-550 \mathrm{mbsf} ; 905: 700-800+\text { mbsf }\end{array}$ & $1,2,3$ \\
\hline Pyrite & Pervasive & 1,3 \\
\hline Quartz $(\alpha)$ & Pervasive & $1,2,3$ \\
\hline Siderite & $\begin{array}{l}902: 200-650 \mathrm{mbsf} ; 903: 700-1000 \mathrm{mbsf} \text {, } \\
\text { 904: } 100-350 \mathrm{mbsf}\end{array}$ & $1,2,3$ \\
\hline Smectite & $\begin{array}{l}\text { 903: } 750-1150 \text { mbsf; } 904: 300-540 \text { mbsf; } \\
\text { 905: } 200-900 \text { mbsf }\end{array}$ & 2,3 \\
\hline
\end{tabular}

Notes: Mineral types are listed along with the location of their main occurrences and sources of identification. Main occurrences refer to Leg 150 sites (e.g., Sites 902, 903 , etc.) and depth in meters below seafloor (mbsf) where the given mineral was identified by XRD analyses. Pervasive occurrences are those found too often to be listed in this table. References include (1) Mountain, Miller, Blum, et al. (1994, see individual site chapters), (2) J.C. Deconinck (pers. comm., 1994), and (3) this study. 
electric cross sections set them apart from all other minerals found in the sediments of Leg 150; thus, they may be modeled as one endmember. Sedimentologically, the presence of these authigenic sedimentary minerals has important ramifications regarding early-diagenetic conditions.

Porosity: Because the fluids contained within the pore space of the rock contribute significantly to the overall physical properties of the sediment, they must be incorporated into the model. Although inversion modeling estimates weight percentages of the sediment consisting of salt water, these estimates can be considered a measure of sediment porosity because all salt water is assumed to reside within the sediments pores.

Pores are assumed to be filled with salt water with $100 \% \circ \mathrm{NaCl}$ salinity. Although this salinity is approximately $40 \%$ greater than average salinities reported by the shipboard inorganic geochemist (cf. Mountain, Miller, Blum, et al., 1994, see individual site chapters), it represents the closest match of previously published logging parameters for saline solutions and the salinities measured during Leg 150 . Because the logging parameters for salt water are well defined and dramatically different from all other end-members used in this study, the effect of this approximation should be negligible on modeling accuracy.

Collectively, these six components make ideal model end-members because they contain valuable geologic information and have unique physical and compositional properties. Thus, they may be exploited by a log inversion model to assess the concentration of each component in any unit volume of sediment. Several minerals, namely amphibole, chlorite, and dolomite, are excluded from the model. Their limited distribution (they occur mostly at shallow burial depths where log data are unavailable) allows this exclusion.

Additional sedimentological information could be gained by separating the glauconite from the clay-rich sediments and distinguishing between siderite and pyrite. These minerals, sometimes found as authigenetically precipitated disseminated crystals and nodules (Mountain, Miller, Blum, et al., 1994, see individual site chapters), also contain valuable stratigraphic information about different depositional conditions. However, as shown below, further subdivision is impractical for this study.

\section{Downhole Logs for Inversion Modeling}

A uniquely determined inversion model capable of modeling the six component system outlined above requires at least five log responses. Three logs were immediately identified as useful inputs. They included the log bulk density (RHOB), the photoelectric cross section (U, where $\mathrm{U}=\mathrm{Pe}$ [photoelectric $\log ] \times[(\mathrm{RHOB}+0.1883) /$ $1.0704])$, and the neutron porosity $\log \left(\phi_{n}\right.$ or NPHI). These three have unique $\log$ responses to all six components and are used commonly in inversion models (cf. Doveton, 1986; Schlumberger, 1987a).

Other useful $\log$ responses include the thorium and potassium logs from the NGT log. Thorium (Thor) is a strong indicator of shale content (Doveton, 1986; Schwalbach and Bohacs, 1992). Potassium (Pota) is a secondary indicator of shale content (Doveton, 1986), and a strong indicator of detritus (Issacs, 1981, in Schwalbach and Bohacs, 1992). Potassium has particularly high responses within the sandstone intervals in Leg 150.

Several logs were specifically excluded from this study. Among these were the spontaneous potential, induction, NGT-uranium, sonic velocity, and GLT log responses. Spontaneous potential and induction logs generally respond poorly to lithology; they better represent fluid properties and permeability (Schlumberger, 1987a). Uranium often corresponds to organic matter in the sediments (e.g., Schmoker and Hester, 1983; Schwalbach and Bohacs, 1992), which is distributed irrespective of lithology in Leg 150 cores (Hesselbo, this volume). Consequently, the NGT-uranium and SGR logs were also excluded. The sonic velocity log was not used because shipboard compression- al velocity measurements were highly questionable; many sediments would not transmit compressional velocities through the Hamilton Frame or P-Wave Logger and, in many other cases, the recorded velocities were slower than water (Mountain, Miller, Blum, et al., 1994, see individual site chapters), a nearly impossible condition for the sediments recovered during Leg 150 . This casts serious doubt on its accuracy and prohibits verifying the sonic log's accuracy with coremeasured data. Finally, as explained earlier, the GLT $\log$ (run only on Hole 906A) was not used.

Thus, the six component model appears favored from a logistical viewpoint: the maximum number of unique log responses available (for all holes) for inversion is limited to five, which limits the number of components to six.

The validity of a six component log model was tested by comparison of the goodness-of-fit of four, five, and six log responses regressed against core porosities. Recall that one of the requirements of the inversion method used in this study is good correlation among core properties and log responses. If inversion is attempted with too few or many log responses, the goodness-of-fit between core and log data, and consequently the accuracy of the inversion results, will degrade. Table 2 shows that the accuracy of the model using three to six $\log$ responses is approximately equal and excellent. Therefore, up to six lithotype components may be modeled without any degradation of the accuracy of the results (assuming that the component log response input parameters of all six components can be accurately estimated).

\section{End-Member Log Parameters}

After appropriate end-member lithologies and logs for inversion modeling were selected, log response parameters were chosen. $\mathrm{Pa}$ rameters were taken from the Gearhart Formation Evaluation Data Handbook (1978), Schlumberger's Interpretation Principles/Applications (1987a, chapter 6) and Log Interpretation Charts (1987b, appendix B), Serra et al. (1980), core-measured properties, and observed log responses. Published parameters were assumed to be most likely values, which were then modified according to observed core and $\log$ values. The ranges and means of these properties are shown in Figure 8.

The accuracy of log response parameters is of paramount importance to the inversion model. The modifications derived previously in this paper simplified the process of accurately estimating log response parameters. For Leg 150, end-member grain densities were known with some confidence. Therefore, Equations 5A and 5B were used to adjust most-likely neutron porosity, photoelectric cross sections, thorium, and potassium properties to match grain densities measured on cores. Relatively minor adjustments were generally re-

Table 2. Precision of various multicomponent inversion models using core porosity and downhole log data from Leg 150.

\begin{tabular}{cccccccc}
\hline & \multicolumn{7}{c}{ Log responses } \\
\cline { 2 - 5 } $\begin{array}{c}\text { Number of } \\
\text { components }\end{array}$ & RHOB & U & NPHI & THOR & POTA & \multirow{2}{*}{ R $^{2}$} & SE \\
\hline 4 & X & X & X & & & 0.8938 & 0.0354 \\
4 & X & & X & X & & 0.9063 & 0.0333 \\
4 & X & X & & X & & 0.8998 & 0.0344 \\
5 & X & X & X & X & & 0.9069 & 0.0333 \\
5 & X & & X & X & X & 0.9066 & 0.0333 \\
5 & X & X & & X & X & 0.8998 & 0.0345 \\
6 & X & X & X & X & X & 0.9071 & 0.0333 \\
\hline
\end{tabular}

Notes: "Number of components" = number of end-members modeled using the logs indicated under "Log responses." Because a uniquely determined inversion model was used in this study, the number of modeled end-members equals the number of selected $\log$ responses plus one. $\mathrm{R}^{2}$ (goodness-of-fit) and SE (standard error) are measures of the precision of the linear regression of the selected log responses against the core porosity data. $\mathrm{RHOB}=\log$ bulk density, $\mathrm{U}=$ photoelectric cross section, $\mathrm{NPHI}=$ neutron porosity $\log . \mathrm{THOR}=$ thorium, and $\mathrm{POTA}=$ potassium . 
quired for the refinements. For example, the best-estimated properties for the terrigenous end-member were: $\mathrm{U}=2.5 \mathrm{ba} / \mathrm{cm}^{3}, \phi_{\mathrm{n}}=-.01$, THOR $=3.25 \mathrm{ppm}$, and POTA $=4.75 \%$. After application of equations (5), the final end-member parameters are: $U=2.2 \mathrm{ba} / \mathrm{cm}^{3}, \phi_{1}=$ 0.0068, THOR $=2.5 \mathrm{ppm}$, and POTA $=5.00 \%$. These parameters, produced through an iterative "estimate and check" process, yield a calculated terrigenous grain density of $2.66 \mathrm{~g} / \mathrm{cm}^{3}$. This density lies within the range of those measure by gravimetric core analyses on cores from Leg 150 and is virtually the same as the $2.65 \mathrm{~g} / \mathrm{cm}^{3}$ " mostlikely" density for this end-member.

Final model input parameters are listed in Table 3. The parameters listed in Table 3 are not the only combination of log response parameters which yield grain densities near the measurements from core. They are, however, the estimates that require the least amount of adjustment to match published and observed estimates. Their overall accuracy is discussed later in this paper.

\section{MODEL CONSTRUCTION}

The inversion model was developed using 140 core porosity measurements and their corresponding log responses. These data represent most major lithotypes and were selected not only because they best represented major lithology types, but also because they represented significant lithologic transitions and intervals with good log responses. Sampling lithologic transitions minimizes the number of samples needed to accurately model two different end-members, and good log responses provide optimal data for the regression of core porosities and $\log$ responses.

Sampled intervals used for modeling included $285-315 \mathrm{mbsf}$ in Hole 904A and 505-525 mbsf in Hole 906A, which both exhibit sharp transitions between biosiliceous and calcareous mudstones, and 140-150 mbsf in Hole 906A, which exhibits a transition from terrigenous to biosiliceous sediments. Sampled intervals were at least $10 \mathrm{~m}$ in length to allow for a good core-to-log fit and minimize the averaging effects of most downhole logs. Depth matching log to core data was practiced rigorously before linear regression. After depth matching, log data were interpolated and resampled at the depths of core porosity analyses to ensure that core and log data represented exactly depth-equivalent sediments. Resulting regression coefficients were inserted into Equations $5 \mathrm{~A}$ and $5 \mathrm{~B}$ and appropriate log response parameters were calculated. Finally, log response parameters were inserted into Equations $1 \mathrm{~A}-1 \mathrm{C}$ and fractions of the six end-member components were calculated by matrix inversion.
Compositions were only calculated where the caliper log indicated good hole conditions. Leg 150 downhole logging tools were calibrated for holes of $11 \mathrm{in}$. $(27.94 \mathrm{~cm})$ diameter; therefore, modeling results from intervals corresponding to caliper values of approximately 11 in. $(27.94 \mathrm{~cm})$ are the most reliable. Compositional calculations were not performed for intervals where the caliper log exceeds $17 \mathrm{in}$. $(43.18 \mathrm{~cm})$ or falls lower than $4 \mathrm{in} .(10.16 \mathrm{~cm})$. This is because the variability of environmental effects on the density, porosity, and gamma-ray logs under these conditions causes questionable log responses. Thus, rather than creating unreliable modeling results from intervals with bad hole conditions, I chose not to evaluate the composition of those intervals.

Potential pitfalls of this model include the nonrepresentation of all major lithotypes, and the use of core and log data from only two sites. With respect to the former point, the model fails to incorporate an interval with a substantial heavy-mineral or chalk end-member. This is mostly because intervals with substantial heavy mineral concentrations (as denoted by the shipboard sedimentologists' lithostratigraphic records) correspond to intervals with poor logging data, and core porosity measurements from most chalk intervals were suspect due to post-cruise drying (although chalk porosities were later shown to be valid; see Fig. 2). However, semiquantitative XRD data indicate that the interval between 285 and 315 mbsf at Hole 904A does contain up to $16 \mathrm{wt} \%$ "heavies" and up to $20 \mathrm{wt} \%$ calcite in calcareous mudstones. It was later found, with the assistance of semiquantitative XRD, that the data acquired from Hole 904A approximated the chalk and heavy end-members very well.

Data were used primarily from Holes 904A and 906A. Core recovery and $\log$ quality at those locations were generally far superior to that of the other sites. Incorporation of data from other sites may have increased the cosmopolitan nature of the input data, but would have probably degraded the quality of the core to log fit.

Table 3. Final log response parameters.

\begin{tabular}{lccrrr}
\hline End-member & $\begin{array}{c}\mathrm{RHOG} \\
\left(\mathrm{g} / \mathrm{cm}^{3}\right)\end{array}$ & $\begin{array}{c}\mathrm{U} \\
\left(\mathrm{ba} / \mathrm{cm}^{3}\right)\end{array}$ & \multicolumn{1}{c}{$\begin{array}{c}\mathrm{NPHI} \\
(\%)\end{array}$} & $\begin{array}{c}\text { THOR } \\
(\mathrm{ppm})\end{array}$ & \multicolumn{1}{c}{$\begin{array}{c}\mathrm{K} \\
(\%)\end{array}$} \\
\hline Terrigenous & 2.66 & 2.2 & 0.0068 & 2.5 & 5.0 \\
Opaline & 2.22 & 4.8 & 0.0290 & 0.0 & 0.0 \\
Calcareous & 2.73 & 5.1 & -0.0012 & 9.0 & -0.1 \\
Argillaceous & 2.43 & 4.1 & 0.0016 & 21.0 & 3.0 \\
Heavy & 3.91 & 61.0 & -0.0300 & 0.0 & 0.1 \\
\hline
\end{tabular}

Note: A detailed discussion of the derivation of these parameters is given in the text.

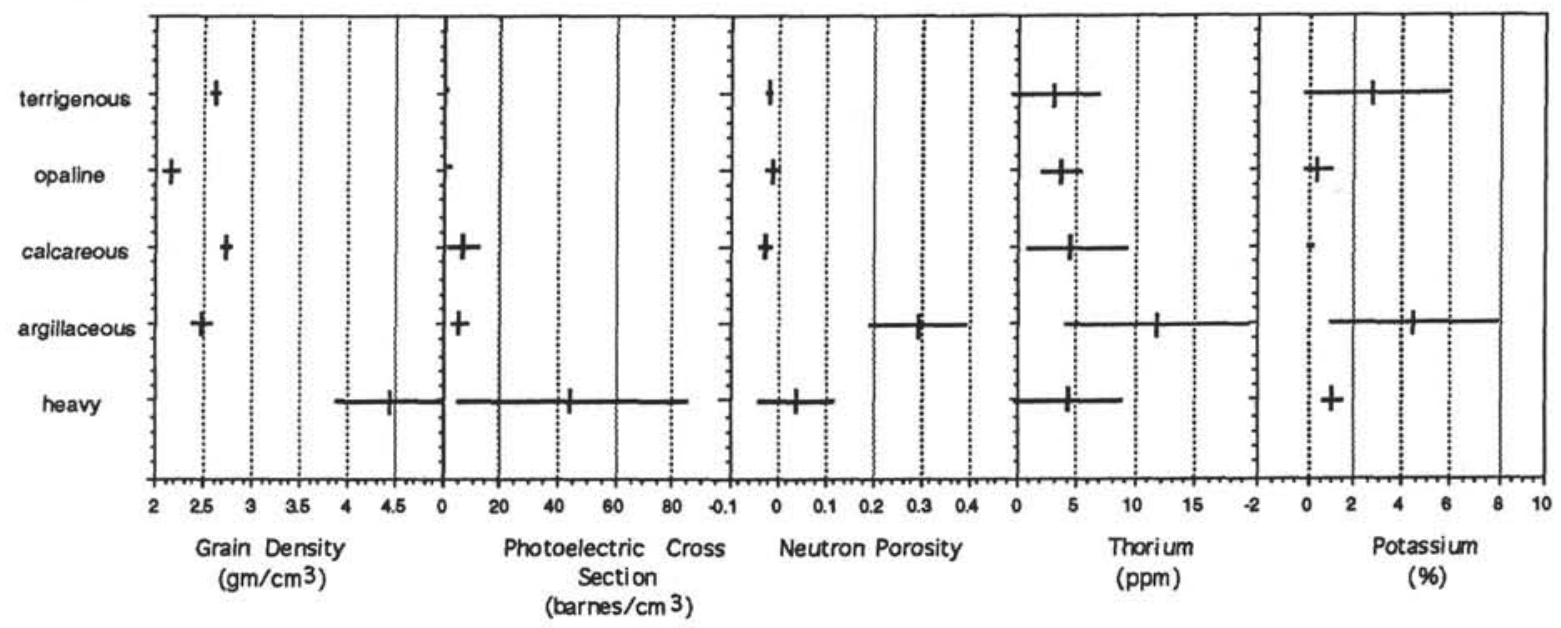

Figure 8. Ranges of log response parameters. Log response parameters are plotted for each proposed end-member lithotype. Data are estimated from published mineral log response parameters in Schlumberger (1987b) and Serra et al. (1980), as well as from observed ranges in downhole log data from Leg 150. 
Modeling was performed on a Apple Macintosh computer using Microsoft Excel 4.0 software. One spreadsheet was used to perform the necessary regressions, parameter estimations, and matrix transpositions and inversions as well as to estimate the total percentage of each component. Individual spreadsheets were constructed for Holes 902D, 903A, 903C, 904A, 905A, and 906A.

\section{MODEL ACCURACY}

The validity and accuracy of the inversion model was evaluated by seven different qualitative and quantitative tests. All tests indicate that the model input parameters and results are both reasonable and accurate. Although rigorous statistical analyses (i.e., calculating a mean absolute log deviation) of the accuracy of the modeling results are not possible in exact linear inversion models (Doveton 1986; Fisher et al., 1992), combined independent and internal tests overwhelmingly indicate the modeling results accurately portray the lithology of the logged intervals. Each test is described in detail below.

\section{Independent Checks}

Two independent checks, involving comparisons of modeling results to data not derived from physical properties of cores, were performed to test the accuracy of the inverse modeling. The checks involved XRD analyses and shipboard sedimentological descriptions; each is described below.

Modeling results were compared with mineralogical estimates from 47 XRD analyses. XRD analyses were performed on a NorelcoPhilips X-ray diffractometer located at the University of California, Santa Cruz, using copper K- $\alpha$ radiation on back-filled powder mounts of freeze-dried specimens uniformly ground to $<<10 \mu \mathrm{m}$ crystallite size and mixed with similarly ground Aldrich $\alpha$-corundum (see Bish and Reynolds, 1989, for the exact methods of sample preparation). Mineral phases were identified manually using the Hanawalt Method (Hanawalt, 1983), and the Chung Method (Chung, 1974a, 1974b) was used to determine semiquantitative mineralogical estimates. Internal references for quartz, calcite, glauconite, opal-A, and opal-CT were created from refined Leg 150 samples; the remaining reference intensity ratios were taken from Bayliss (1986). As such, semiquantitative mineralogical estimates are as good as $7 \mathrm{wt} \%$ for the five minerals listed above and only as good as $\pm 30 \mathrm{wt} \%$ for the remaining minerals (Bayliss, 1986). However, as the five minerals listed above constitute the majority fraction (approximately twothirds) of minerals in most samples, excluding claystones, the overall accuracy of the XRD analyses should be between 11 and 16 wt \%. Final XRD results, presented in fractional form, were normalized to 1 and are presented in Table 4.

Mineral estimates from semiquantitative XRD were credited to end-member categories and converted to fractions of the whole rock using core porosity data. These compositional estimates were then plotted against compositional estimates from the inversion model. Results are shown on modeling summary plots (Figs. 9-13). Agreement between these two independent estimates of lithology are excellent. Most XRD results fall within $10 \mathrm{wt} \%$ of the inversion results; because this is the maximum accuracy of the XRD method, it is impossible to state which method more accurately represents the true lithology at the depth of the analysis.

A second independent test of the accuracy of the inversion results is by visual comparison to the shipboard sedimentological descriptions and petrographic analyses. Comparisons of the modeling results to the sedimentary descriptions are shown on Figures 9 through 13. Modeling results are verified by several observations. First, note the close correspondence of major grain size shifts to terrigenous volume. For example, large sandstone beds around $360 \mathrm{mbsf}$ in Hole 903A and 340 mbsf in Hole 904A correspond directly to highly ele- vated terrigenous concentrations. While the relationship between textural properties (grain size) and compositional properties (lithology) is commonly known to be inconsistent, it is reassuring to the results of this study to see the beds with larger grain sizes corresponding to beds composed of detrital clastic minerals.

Lithologic observations from the shipboard sedimentological descriptions also verify inversion modeling results. Shipboard sedimentologists always noted the presence of distinctive lithologic components (i.e., glauconite, siderite, diatom frustules, etc.). Comparison of intervals with abundant concentrations of these components to inversion modeling results compares well. For example, an interval with numerous siderite and pyrite nodules (260-285 mbsf, Hole 906A; see Fig. 13) corresponds closely with an interval of elevated heavy mineral modeling results. The model also does a good job of recognizing Eocene chalks and porcelanites (see Fig. 12). The overall agreement between these two records is therefore very good.

\section{Internal Checks}

Several tests involve numerical comparison of modeling inputs and results to core data and theoretical constraints. These tests include comparison of model and core porosity and grain density, comparison of theoretical to practical log response parameters, and checks to ensure that all results fall between 0 and $100 \mathrm{wt} \%$. Each test is discussed in detail below.

As already discussed, the measure of the goodness-of-fit (Table 2) between log and core data is excellent. A good fit ensures that core porosity will be properly modeled. Figure 14 illustrates that model porosity does match core porosity very well. The goodness-of-fit was also found to be an indicator of how well the total sum of all compositional elements approaches unity. The maximum deviation from unity using the six-component model was 0.003 , and it averaged 0.0015 ; therefore, the modeling constraint that requires the sum of the modeled components to equal unity is always met.

A better numerical check of core and modeling results is by comparison of calculated model grain densities and those measured directly from core. The failure of core and model grain density to closely track each other (Fig. 15) came as no surprise. Gravimetric core grain density data are of questionable accuracy (Mountain, Miller, Blum, et al., 1994, see "Site 903" chapter); therefore, this direct comparison is not applicable.

Another qualitative check of the model's accuracy is by the realism of the log response input parameters (Table 3 ). Note that these parameters, with the exception of the $\phi_{n}$ parameter of the clay endmember, all fall within their respective predicted ranges. The failure of the clay end-member's $\phi_{n}$ value to fall within its predicted range is disconcerting: No valid explanation exists for this condition. Realistic values were attempted for this parameter, but they forced the clay's grain density to rise to approximately $2.7-2.8 \mathrm{~g} / \mathrm{cm}^{3}$. With the predominance of illite and kaolinite in the Leg 150 clays (Deconinck and Vanderaveroet, this volume), this is an unlikely grain density. However, in light of the aforementioned evidence that the results are otherwise valid, the fact that 24 of the 25 requisite log response parameters fall within their predicted range, and that true $\phi_{n}$ of the clay cannot be ascertained for direct comparison, this error is acknowledged as part of the model but not dealt with further.

As suggested by Harvey et. al. (1990; also see Fisher et al., 1992), the sum of all negative errors is a good measure of the accuracy of modeling results and was therefore calculated for all modeling results. Recall that all results must obey the constraint of being physically reasonable; that is, lithologic estimates must be greater or equal to zero and less than or equal to unity minus porosity. No modeling results failed the latter of these constraints although some results did fall below $0 \mathrm{wt} \%$. This is the result of inherent imprecisions in the design of the model (i.e., the goodness-of-fit was less than unity, porosity data from diatomaceous mudstones was not rebound corrected, 
Table 4. Results from semiquantitative X-ray diffraction analyses.

\begin{tabular}{|c|c|c|c|c|c|c|c|c|c|c|c|c|c|c|c|c|}
\hline $\begin{array}{l}\text { Core, section, } \\
\text { interval }(\mathrm{cm})\end{array}$ & $\begin{array}{l}\text { Depth } \\
\text { (mbsf) }\end{array}$ & Smectite & Glauconite & Illite & $\begin{array}{l}\text { Illite- } \\
\text { smectite }\end{array}$ & Kaolinite & $\begin{array}{c}\text { Opal- } \\
\text { A }\end{array}$ & $\begin{array}{l}\text { Opal- } \\
\text { CT }\end{array}$ & Quartz & Microcline & Muscovite & Albite & Calcite & $\begin{array}{l}\text { High-Mg } \\
\text { calcite }\end{array}$ & Siderite & Pyrite \\
\hline \multicolumn{17}{|l|}{ 150-902D- } \\
\hline $27 X-7,13-15$ & 237.93 & & & 0.330 & 0.020 & 0.130 & 0.110 & & 0.270 & 0.040 & & 0.050 & & tr & 0.060 & \\
\hline 28X-1,99-101 & 239.39 & & & 0.230 & 0.040 & 0.140 & 0.100 & & 0.330 & 0.030 & & 0.060 & & 0.020 & 0.060 & \\
\hline $56 \mathrm{X}-2,116-118$ & 509.86 & 0.058 & & 0.153 & 0.026 & 0.061 & 0.248 & & 0.236 & 0.045 & & 0.038 & & 0.025 & 0.067 & 0.040 \\
\hline $74 X-3,61-63$ & 683.81 & tr & & 0.020 & 0.010 & 0.010 & & 0.13 & 0.120 & 0.020 & & 0.020 & 0.680 & & & \\
\hline $74 X-5,121-123$ & 687.41 & 0.050 & & 0.040 & 0.010 & 0.010 & & 0.14 & 0.150 & tr & & 0.010 & 0.600 & & & \\
\hline \multicolumn{17}{|l|}{$150-903 \mathrm{~A}-$} \\
\hline $\begin{array}{l}40 X-3,138-140 \\
40 X-2,66-68\end{array}$ & & & $\begin{array}{l}0.080 \\
0.130\end{array}$ & $\begin{array}{l}0.050 \\
0.040\end{array}$ & 0.090 & 0.010 & & & & 0.040 & 0.09 & & & & & \\
\hline & $\begin{array}{l}348.16 \\
371.16\end{array}$ & $\begin{array}{l}0.010 \\
0.020\end{array}$ & $\begin{array}{l}0.130 \\
0.090\end{array}$ & $\begin{array}{l}0.040 \\
0.050\end{array}$ & 0.040 & 0.070 & & & $\begin{array}{l}0.650 \\
0.570\end{array}$ & 0.050 & & $\begin{array}{l}0.100 \\
0.010\end{array}$ & $\begin{array}{l}0.030 \\
0.030\end{array}$ & & 0.010 & \\
\hline $\begin{array}{l}42 X-4,126-128 \\
43 X-1,113-115\end{array}$ & $\begin{array}{l}371.16 \\
376.03\end{array}$ & 0.020 & $\begin{array}{l}0.090 \\
0.020\end{array}$ & $\begin{array}{l}0.050 \\
0.040\end{array}$ & $\begin{array}{l}0.040 \\
0.020\end{array}$ & $\begin{array}{l}0.070 \\
0.020\end{array}$ & & & $\begin{array}{l}0.570 \\
0.690\end{array}$ & $\begin{array}{l}0.040 \\
0.060\end{array}$ & 0.02 & 0.010 & 0.030 & 0010 & 0.010 & 0.040 \\
\hline & 456.39 & & 0.082 & 0.077 & 0.119 & 0.050 & & & $\begin{array}{l}0.090 \\
0.271\end{array}$ & $\begin{array}{l}0.060 \\
0.022\end{array}$ & & 0.110 & & 0.010 & 0.020 & \\
\hline $\begin{array}{l}51 X-3,119-121 \\
52 X-2,45-47\end{array}$ & 463.85 & & 0.129 & 0.088 & & $\begin{array}{l}0.050 \\
0.073\end{array}$ & & & 0.271 & 0.022 & & 0.037 & & 0.351 & 0.022 & 0.044 \\
\hline & 403.85 & & 0.129 & 0.088 & & 0.073 & & & 0.396 & 0.029 & & 0.079 & & & 0.206 & \\
\hline $73 X-7,46-48$ & 673.56 & & & 0.190 & 0.040 & 0.180 & 0.160 & & 0.260 & 0.050 & & 0.050 & 0.010 & & 0.040 & 0.030 \\
\hline $74 X-1,50-52$ & 674.30 & & & 0.230 & 0.020 & 0.170 & 0.150 & & 0.270 & 0.040 & & 0.040 & 0.010 & & 0.040 & 0.020 \\
\hline $74 X-3,59-61$ & 677.39 & 0.010 & & 0.150 & 0.050 & 0.160 & 0.160 & & 0.280 & 0.040 & & 0.050 & 0.030 & & 0.040 & 0.020 \\
\hline \multicolumn{17}{|l|}{$150-904 \mathrm{~A}-$} \\
\hline $24 \mathrm{H}-4,103-105$ & 218.03 & & 0.090 & 0.080 & & & 0.180 & & 0.570 & 0.030 & & 0.020 & & & 0.030 & \\
\hline $24 \mathrm{H}-6,6-8$ & 220.06 & & 0.060 & 0.100 & & & 0.140 & & 0.510 & 0.080 & & 0.030 & 0.020 & & 0.050 & 0.020 \\
\hline $25 X-5,102-104$ & 229.02 & 0.010 & 0.190 & 0.060 & 0.080 & 0.060 & 0.150 & & 0.250 & 0.030 & & 0.050 & & & 0.040 & 0.070 \\
\hline $32 X-2,37-39$ & 290.97 & & & 0.137 & 0.066 & 0.075 & 0.243 & & 0.166 & 0.040 & & 0.055 & 0.105 & & 0.095 & 0.019 \\
\hline $32 \times-4,148-150$ & 295.08 & & & 0.177 & 0.047 & 0.049 & 0.221 & & 0.164 & 0.050 & & & 0.193 & & 0.085 & 0.015 \\
\hline $32 X-7,4-6$ & 298.14 & & & 0.110 & tr & tr & 0.080 & & 0.130 & 0.030 & & 0.010 & 0.620 & & 0.010 & tr \\
\hline $32 \mathrm{X}-\mathrm{CC}, 23-25$ & 298.81 & & & 0.120 & 0.010 & 0.030 & 0.080 & & 0.090 & 0.010 & & 0.010 & 0.630 & & 0.030 & tr \\
\hline $33 X-1,68-70$ & 299.13 & & & 0.080 & & 0.030 & 0.040 & & 0.060 & 0.040 & & tr & 0.720 & & 0.020 & tr \\
\hline $33 \mathrm{X}-1,139-141$ & 300.19 & & & 0.040 & 0.030 & 0.030 & 0.050 & & 0.160 & 0.010 & & tr & 0.620 & & 0.050 & tr \\
\hline $33 \mathrm{X}-2,56-58$ & 300.86 & & & 0.130 & 0.010 & 0.040 & 0.050 & & 0.080 & 0.010 & & 0.020 & 0.600 & & 0.030 & 0.030 \\
\hline $33 X-2,125-127$ & 301.55 & & & 0.100 & 0.030 & 0.010 & 0.090 & & 0.050 & 0.010 & & 0.010 & 0.680 & & 0.020 & tr \\
\hline $33 X-3,44-46$ & 302.24 & & & 0.080 & 0.060 & 0.060 & 0.070 & & 0.110 & 0.110 & & 0.050 & 0.440 & & 0.020 & tr \\
\hline $37 X-3,11-13$ & 339.61 & & 0.180 & 0.050 & 0.080 & 0.040 & 0.120 & & 0.130 & 0.040 & & 0.020 & 0.250 & & & \\
\hline $37 X-3,27-29$ & 339.77 & & 0.280 & 0.060 & 0.120 & 0.070 & 0.160 & & 0.160 & 0.040 & & 0.050 & 0.220 & & 0.010 & \\
\hline $37 X-3,48-50$ & 339.98 & & 0.320 & 0.050 & 0.050 & 0.010 & 0.150 & & 0.080 & 0.060 & & 0.040 & 0.230 & & & \\
\hline $59 X-2,80-82$ & 540.30 & & & 0.050 & & & & 0.34 & 0.020 & & & & 0.590 & & & \\
\hline $59 \mathrm{X}-3,29-31$ & 541.29 & & & 0.050 & 0.050 & 0.05 & & 0.21 & 0.010 & & & & 0.640 & & & \\
\hline $59 X-5,42-44$ & 544.42 & & & 0.010 & & 0.08 & & 0.26 & 0.010 & & & & 0.640 & & & \\
\hline \multicolumn{17}{|l|}{$150-906 \mathrm{~A}-$} \\
\hline $16 X-4,17-19$ & 144.37 & 0.030 & 0.120 & 0.150 & 0.030 & 0.100 & & & 0.390 & 0.040 & & 0.070 & 0.010 & & 0.030 & 0.020 \\
\hline $16 \times-5,144-146$ & 147.14 & & & 0.240 & 0.040 & 0.120 & 0.160 & & 0.320 & 0.040 & & 0.040 & 0.010 & tr & 0.030 & \\
\hline $25 \times-2,114-116$ & 229.14 & & & 0.180 & 0.103 & 0.168 & 0.183 & & 0.179 & 0.042 & & 0.058 & & & 0.047 & 0.040 \\
\hline $25 \mathrm{X}-4,29-31$ & 231.29 & & 0.059 & 0.189 & 0.042 & 0.152 & 0.213 & & 0.161 & 0.032 & & 0.043 & 0.017 & & 0.045 & 0.045 \\
\hline $28 \mathrm{X}-5,109-111$ & 262.39 & & 0.232 & 0.087 & 0.019 & 0.134 & & & 0.190 & 0.0006 & & 0.024 & & & 0.241 & 0.067 \\
\hline $28 \times-6,67-69$ & 263.47 & & 0.160 & 0.098 & 0.119 & 0.138 & & & 0.105 & 0.031 & & 0.029 & & 0.014 & 0.305 & \\
\hline $51 X-1,98-100$ & 478.18 & & & 0.070 & 0.050 & 0.020 & 0.160 & & 0.250 & 0.030 & & 0.040 & 0.390 & tr & 0.010 & \\
\hline $51 X-4,128-130$ & 482.98 & & & 0.080 & 0.080 & 0.050 & 0.100 & & 0.190 & 0.020 & & 0.060 & 0.390 & tr & 0.010 & \\
\hline $54 \mathrm{X}-1,94-96$ & 507.14 & & 0.010 & 0.130 & 0.110 & 0.060 & 0.180 & & 0.210 & 0.060 & & 0.090 & 0.070 & tr & 0.030 & 0.030 \\
\hline $54 \mathrm{X}-2,84-86$ & 508.54 & & & 0.110 & 0.040 & 0.110 & 0.170 & & 0.240 & 0.040 & & 0.050 & 0.200 & tr & 0.020 & 0.020 \\
\hline $54 X-6,17-19$ & 513.87 & & 0.090 & 0.120 & 0.030 & 0.060 & 0.140 & & 0.270 & 0.050 & & 0.060 & 0.160 & & 0.030 & 0.010 \\
\hline $55 \times-5,30-32$ & 522.10 & & 0.120 & 0.140 & 0.050 & 0.150 & 0.160 & & 0.200 & 0.040 & & 0.050 & 0.020 & & 0.040 & 0.030 \\
\hline
\end{tabular}

Notes: Mineral abundances are presented in weight fractions normalized to one, $\operatorname{tr}(\operatorname{trace})=<0.01$.

and not all minerals found in the sediments were incorporated into the model).

The sum of negative errors is presented along with all corresponding modeling results (Figs. 9-13). Note that this check indicates overall excellent accuracy. Most results in gauge holes have approximately zero sum of negative errors. Errors are only significant $(-0.2$ or more) where caliper logs show non-gauge holes.

In summary, all checks of modeling results indicate they are physically reasonable and accurate to within the precision of independent checks. Some additional work may be necessary to completely remove residual sums of negative errors and bring all log response parameter estimates to within predicted ranges; however, this work is unwarranted unless more precise independent checks of lithology become available and indicate the accuracy of the model needs improvement.

\section{MODELING RESULTS}

Modeling results for all logged holes are shown as Figures 9 through 13. Modeling results are plotted in weight percentages, along with stratigraphic columns taken from the site reports of the Leg 150 Initial Reports volume. Sequence boundaries were provided by G.S.
Mountain (pers. comm., 1994) and Lorenzo and Hesselbo (this volume). Diamond symbols represent the semiquantitative XRD analyses performed on core samples as a check on modeling results.

Below, modeling results are discussed on a hole-by-hole basis within the context of the goals of this study.

\section{Site 902}

Logging data from Hole 902D was used to model the compositional character of mid-slope Site 902. Modeling results are presented in Figure 9.

Although only $15 \mathrm{~m}$ of Eocene-aged sediments were logged, several interesting lithologic properties are evident: a large terrigenous component exists through the upper $5 \mathrm{~m}$, calcite compositions of over $25 \%$ persist to within $5 \mathrm{~m}$ of the lower Oligocene boundary, and opaline concentration is constant and equals approximately $8 \%$.

Oligocene sediments in Hole 902D consist of a fairly high terrigenous component (14\% average), small but persistent opaline concentrations ( $3 \%$ average), highly variable calcite ( $8 \%$ average), moderate and variable clay (18\% average), and a small, invariable heavy fraction ( $7 \%$ average). The most notable feature of this interval is the abrupt decrease of terrigenous material at 648 mbsf in conjunction with a drop in clay volume. Based on observations of sequence 


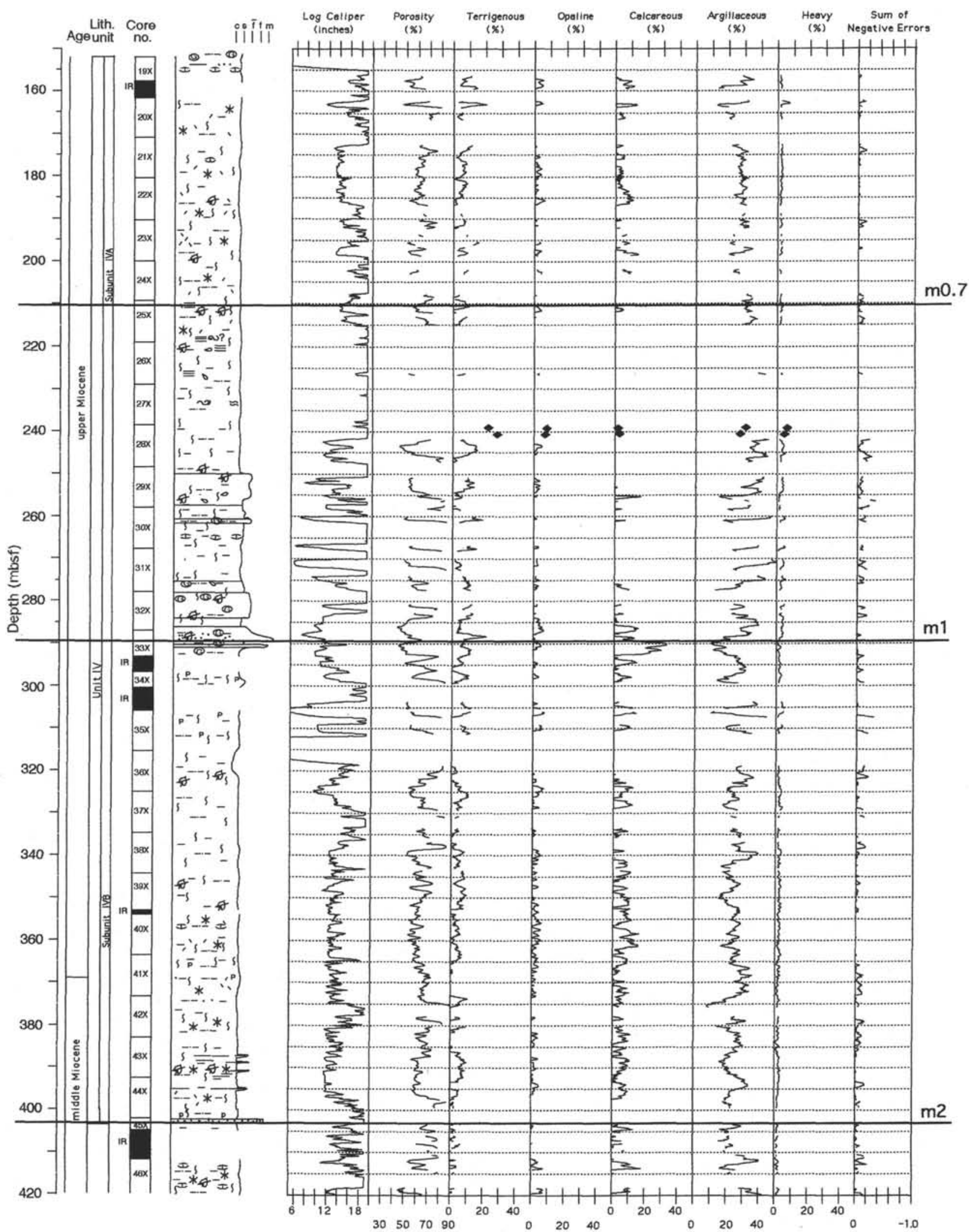

Figure 9. Summary plot of inversion modeling results for Hole 902D. Stratigraphic column is from Mountain, Miller, Blum, et al. (1994, see individual site chapters). Graphic representation is with respect to grain size (e.g., "c" = clay, "m" = medium sand, etc.). The downhole caliper log indicates where modeling results are valid. Modeling results are only valid and shown for hole diameters between 4 and $17 \mathrm{in}$. (10.16-43.18 cm). Modeled compositional end-members, listed across the top of columns two through seven, are presented in weight percentages and described thoroughly in the text. Diamonds represent results from semiquantitative X-ray diffraction analyses. Column eight contains the calculated sum of negative errors, an estimator of modeling accuracy. Sequence boundaries are represented by horizontal lines, labeled at the right by the respective name of the boundary (data from G.S. Mountain, pers. comm., 1994, and Lorenzo and Hesselbo, this volume). 


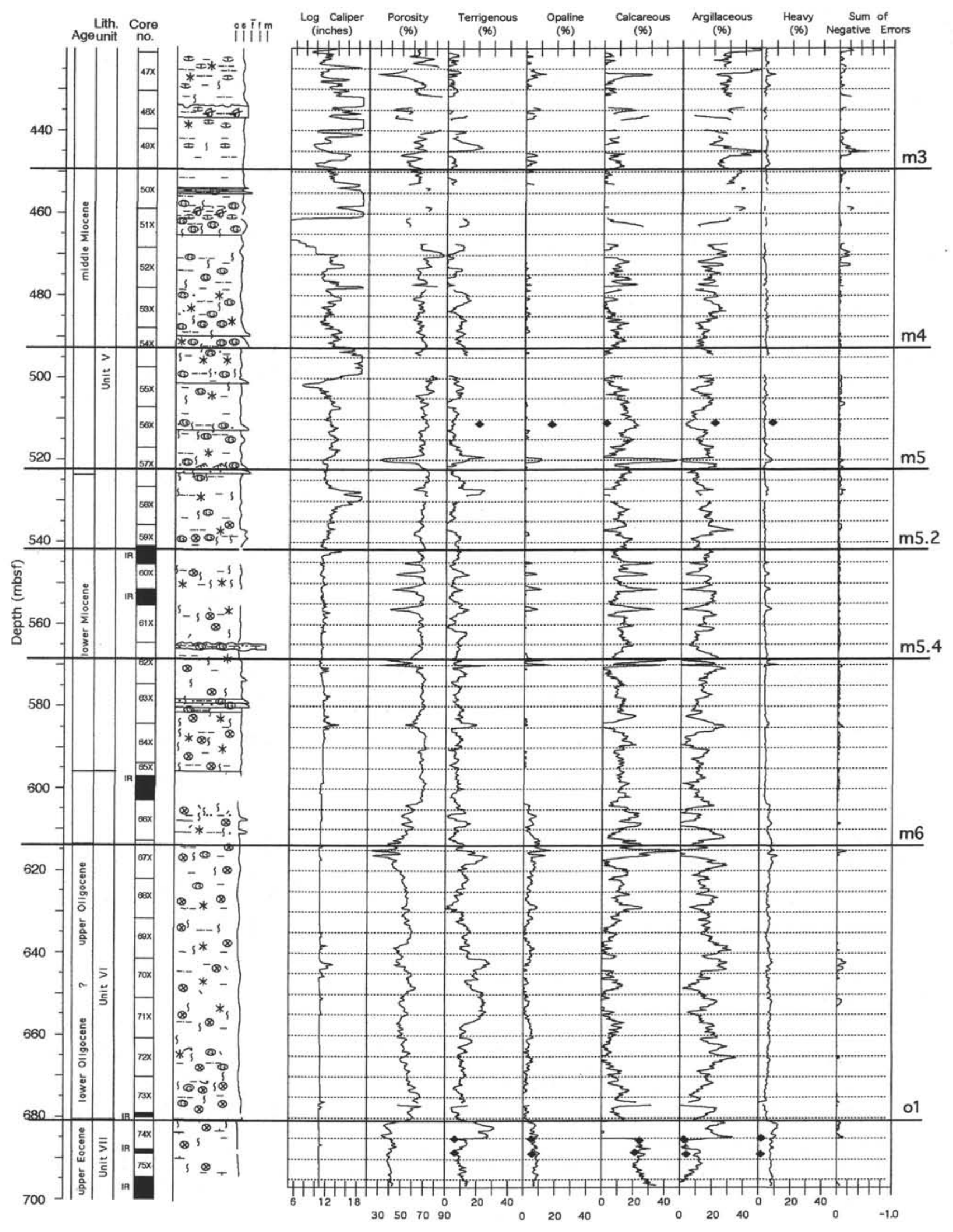

Figure 9 (continued). 


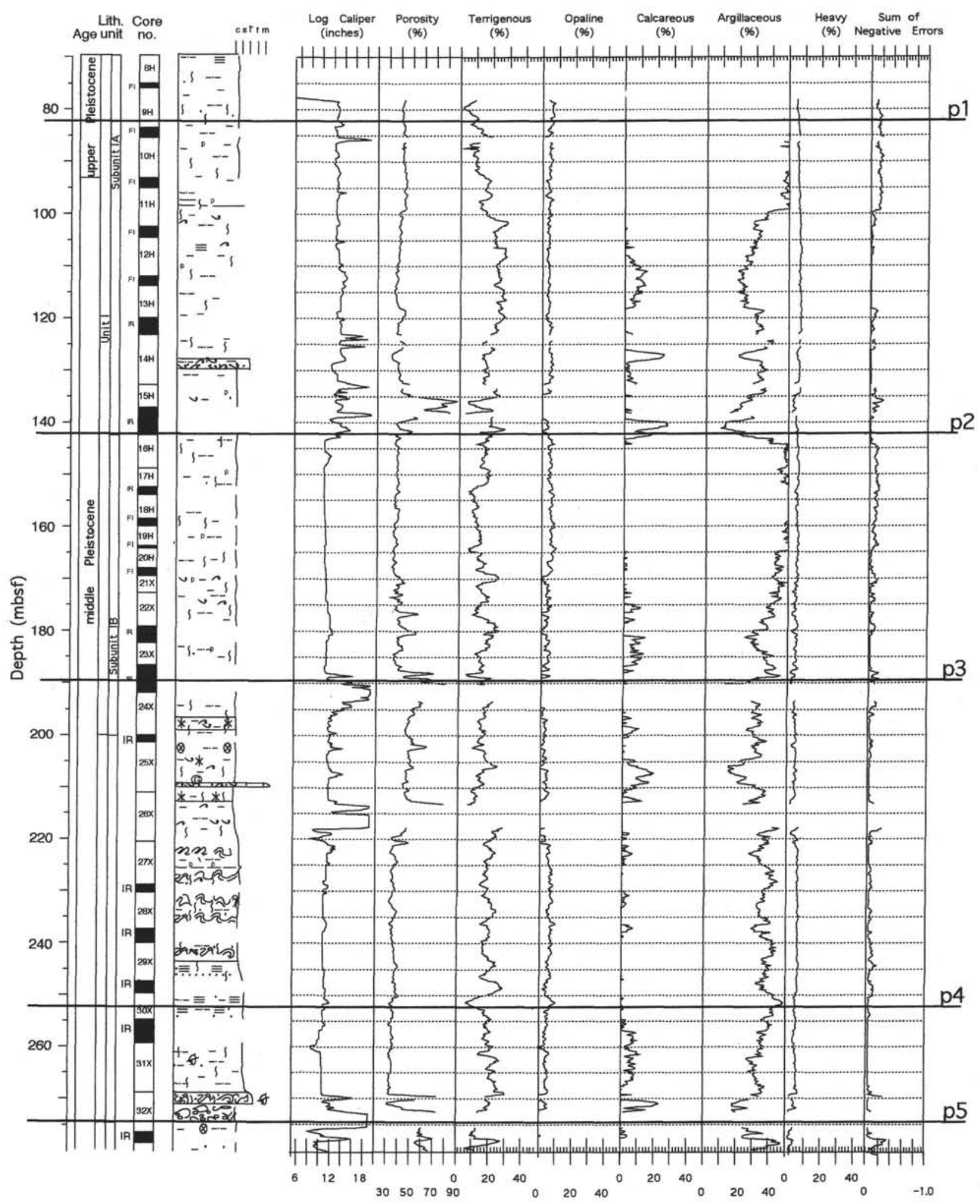

Figure 10. Summary plot of inversion modeling results for Hole 903A. See Figure 9 for descriptions of symbols and plot format. 


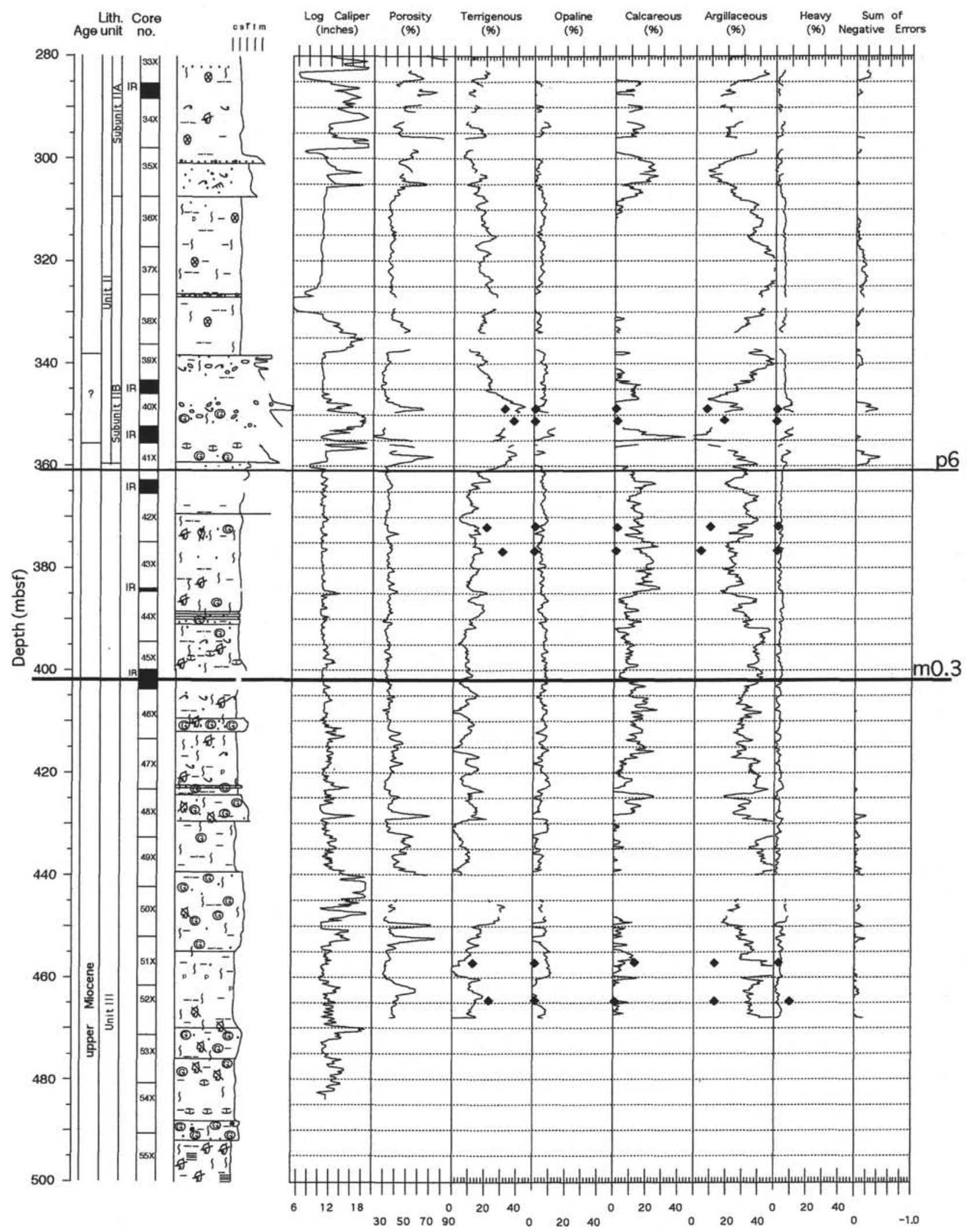

Figure 10 (continued). 


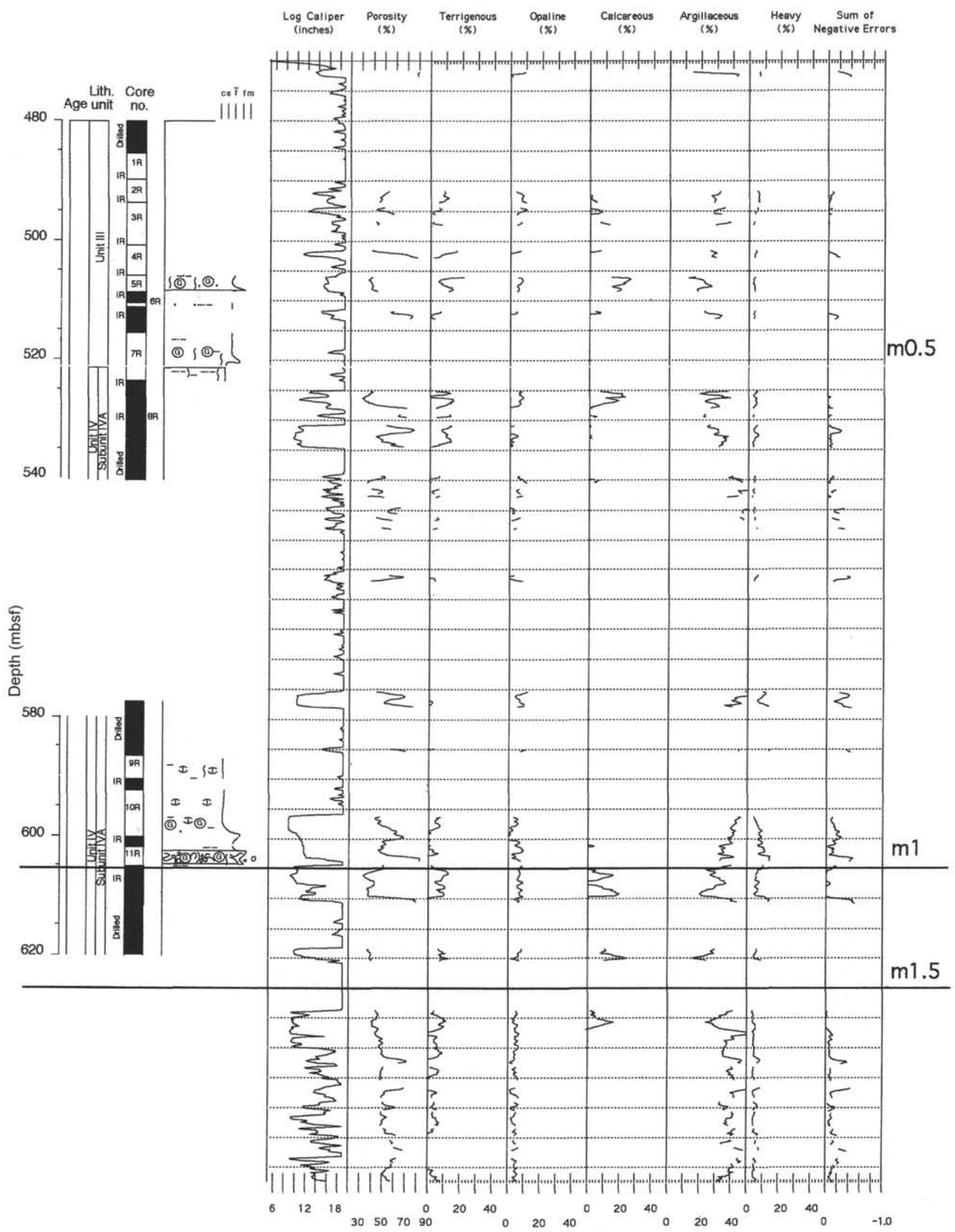

Figure 11. Summary plot of inversion modeling results for Hole 903C. See Figure 9 for descriptions of symbols and plot format. 


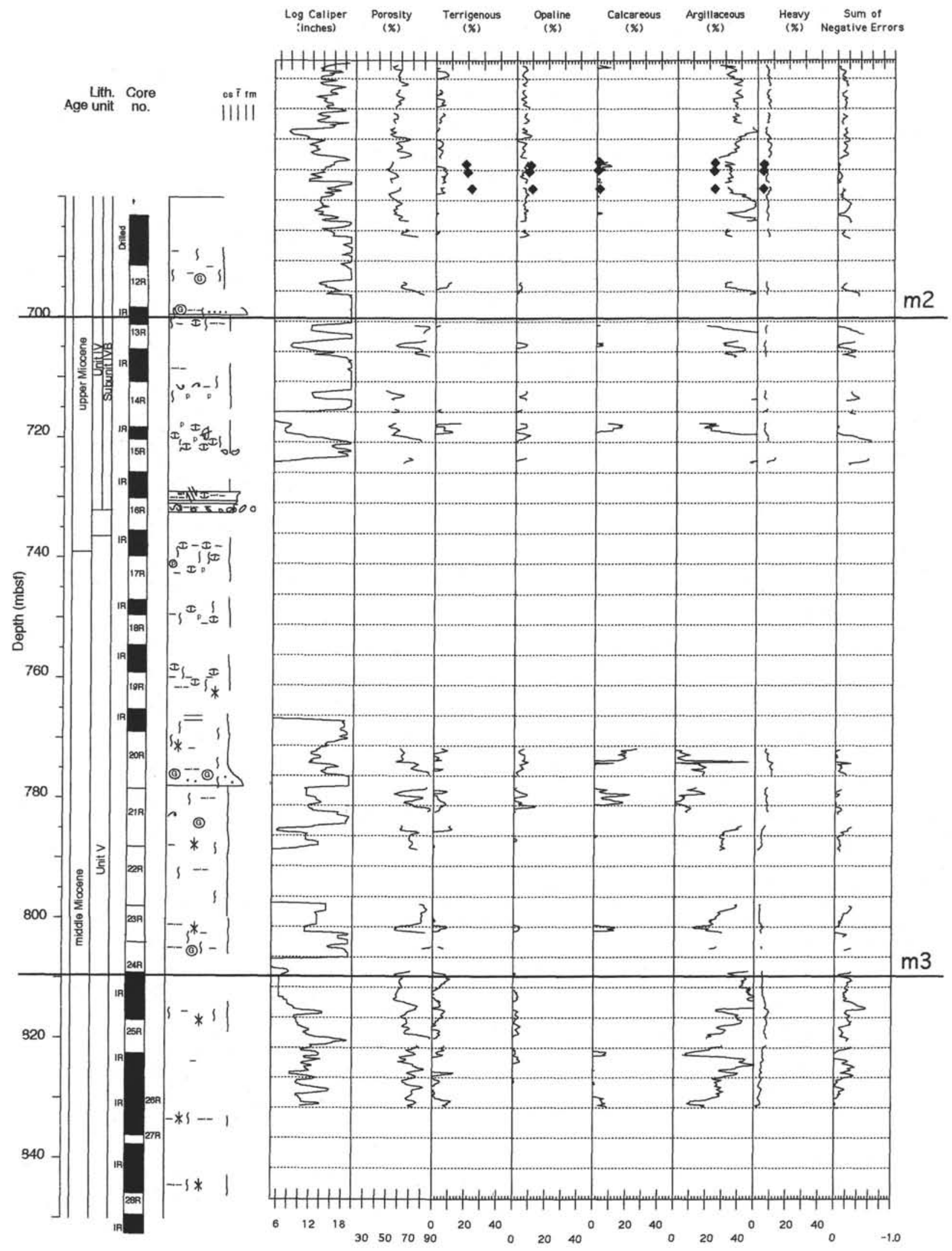

Figure 11 (continued.) 


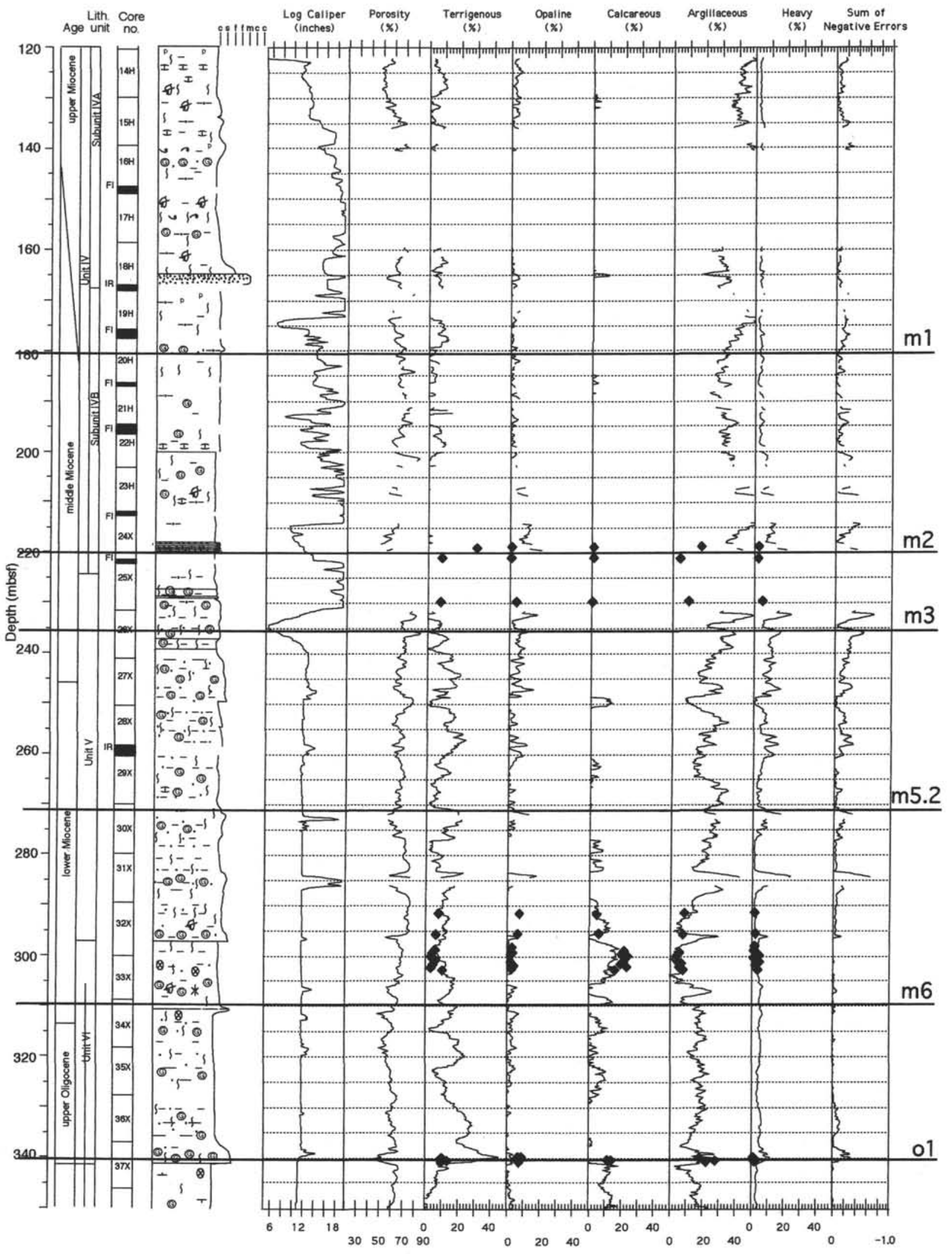

Figure 12. Summary plot of inversion modeling results for Hole 904A. See Figure 9 for descriptions of symbols and plot format. 


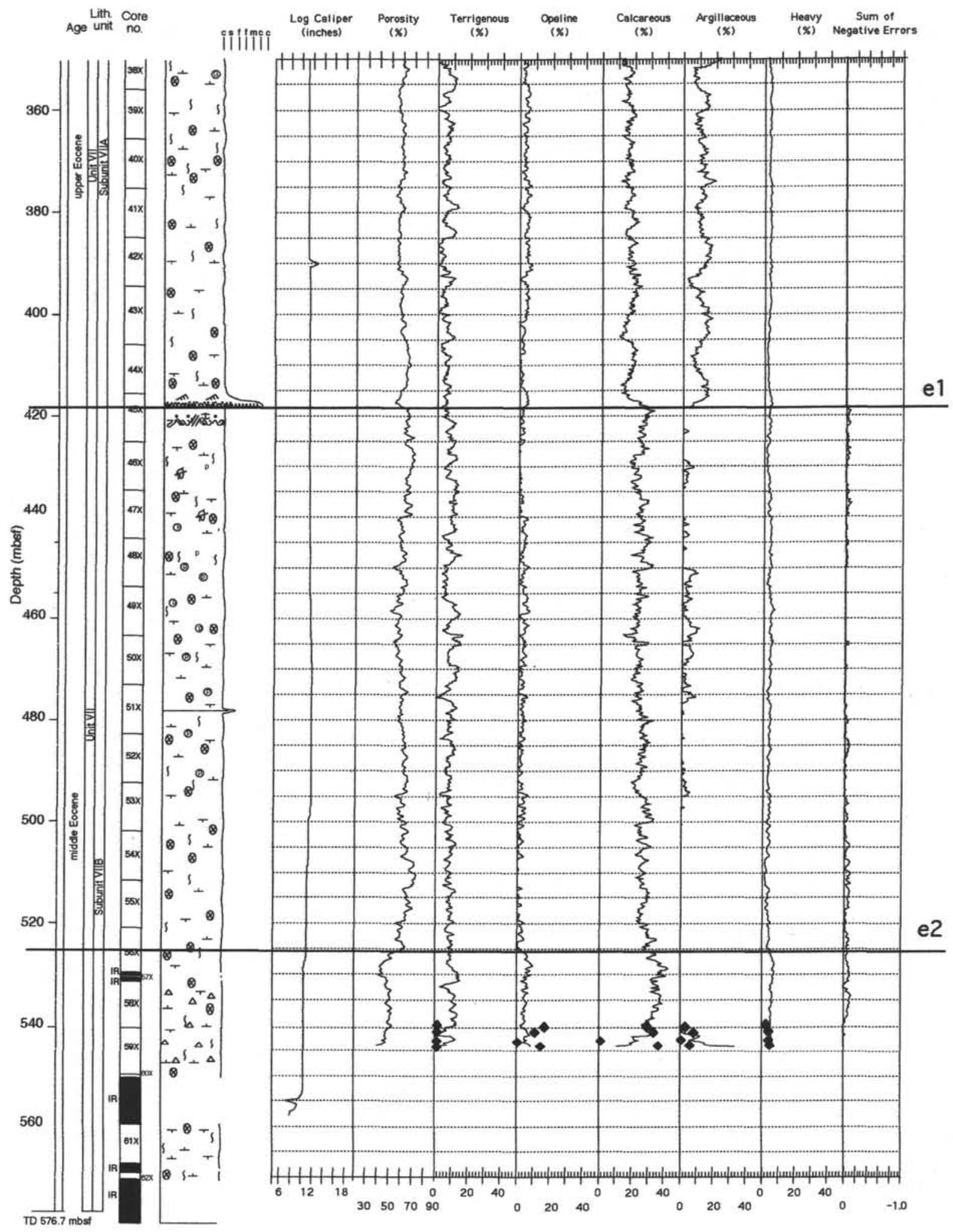

Figure 12 (continued). 


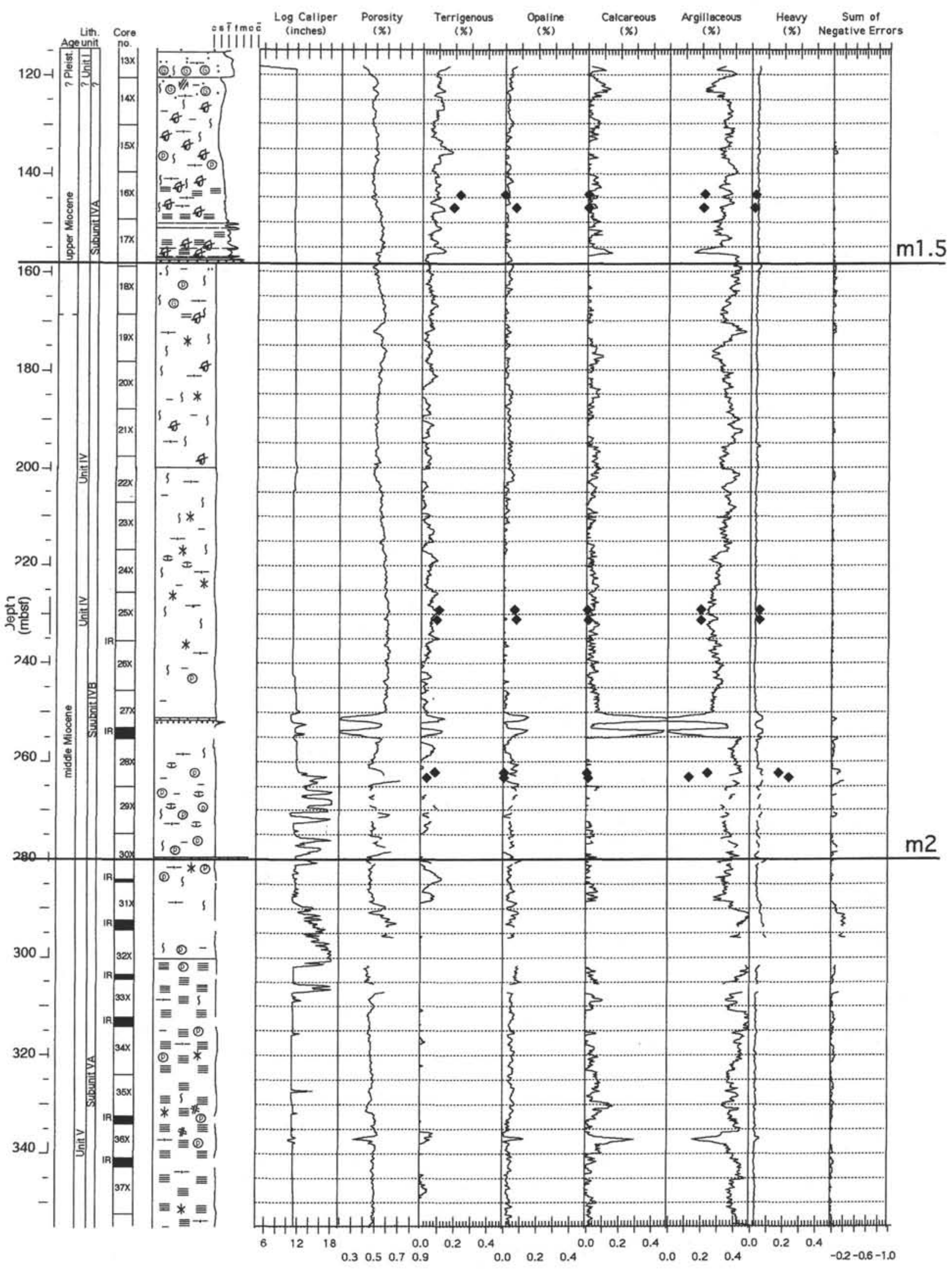

Figure 13. Summary plot of inversion modeling results for Hole 906A. See Figure 9 for descriptions of symbols and plot format. 


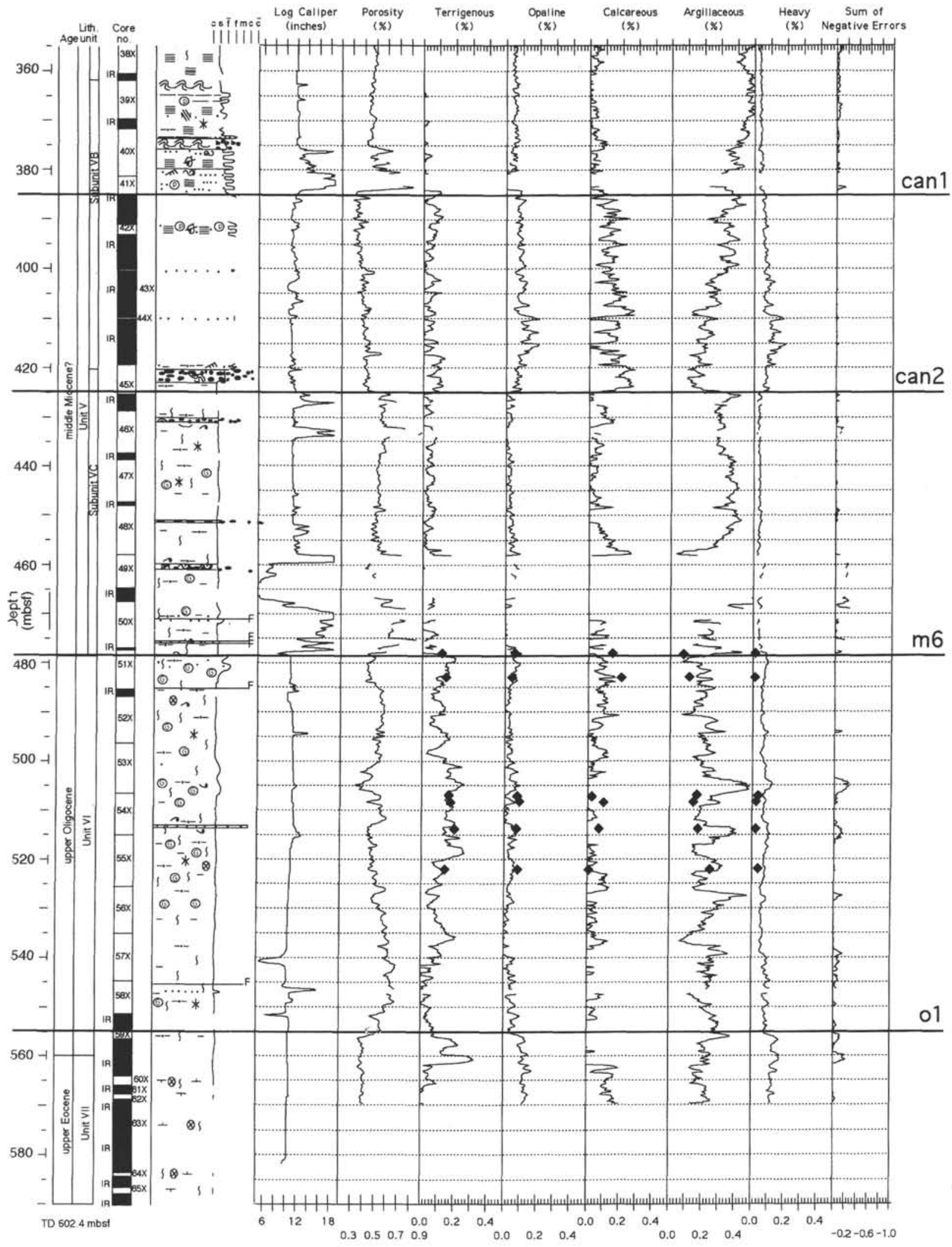

Figure 13 (continued). 
A

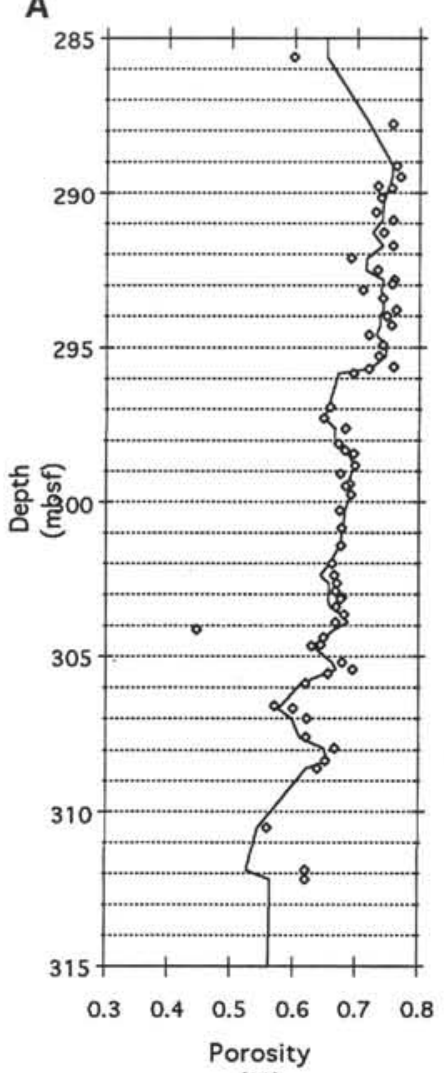

(\%)
B

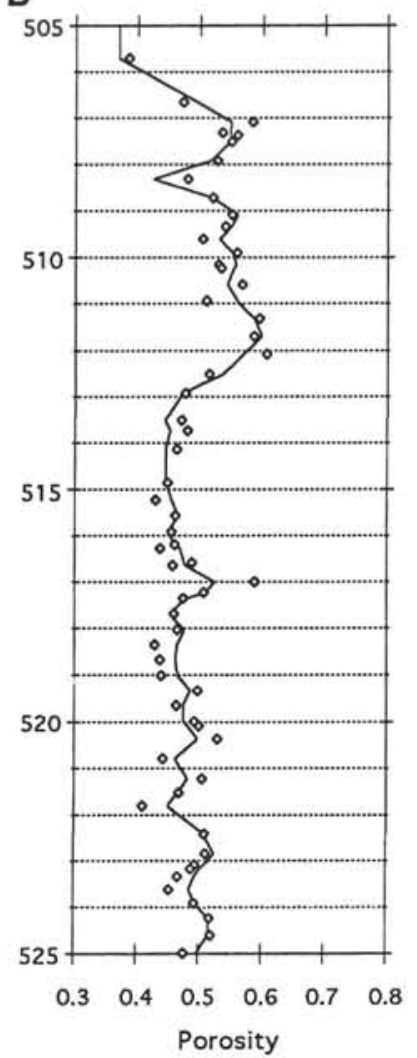

(\%)
Figure 14. Depth plot of core and model porosity. Core measured porosities (diamonds) closely match predicted porosities from inversion modeling (solid line) for Sites 904 (A) and 906 (B).

boundaries at this and other holes, this may indicate the presence of another sequence boundary.

The Miocene section in Hole 902D is thick and contains considerable compositional information. Only a few of the key observations are cited below.

1. Lower Miocene sediments contain slightly lower average terrigenous ( $5 \%$ lower), opaline ( $3 \%$ lower), and clay ( $4 \%$ lower) weight percentages than the underlying Oligocene interval; the difference is made up of increased porosity ( $9 \%$ higher) and calcite ( $3 \%$ higher).

2. Middle Miocene sediments show a significant compositional change. Sediments through the lower one-third of the middle Miocene, like the lower Miocene, contain clays that average $14 \%$ of the sediment. At 462 mbsf, however, clay increases to an average of $24 \%$, and remains high throughout the middle and upper Miocene. The clay increase corresponds to decreases in porosity ( $3 \%$ lower), terrigenous ( $2 \%$ lower), calcite ( $3 \%$ lower), and heavy ( $2 \%$ lower) end-members.

3. Upper Miocene sediments appear compositionally similar to the upper two-thirds of the middle Miocene although this evaluation is limited by poor hole conditions.

Modeling results provide characteristics for several lost core intervals in Hole 902D. For example, the lower half of Core 150-902D$59 \mathrm{X}$ suffered incomplete recovery. Characterization of this interval was of paramount importance because it supposedly contained sequence boundary m5.2. The sequence boundary appears to be composed of terrigenous, opaline, and heavy fractions similar to sedi-
A

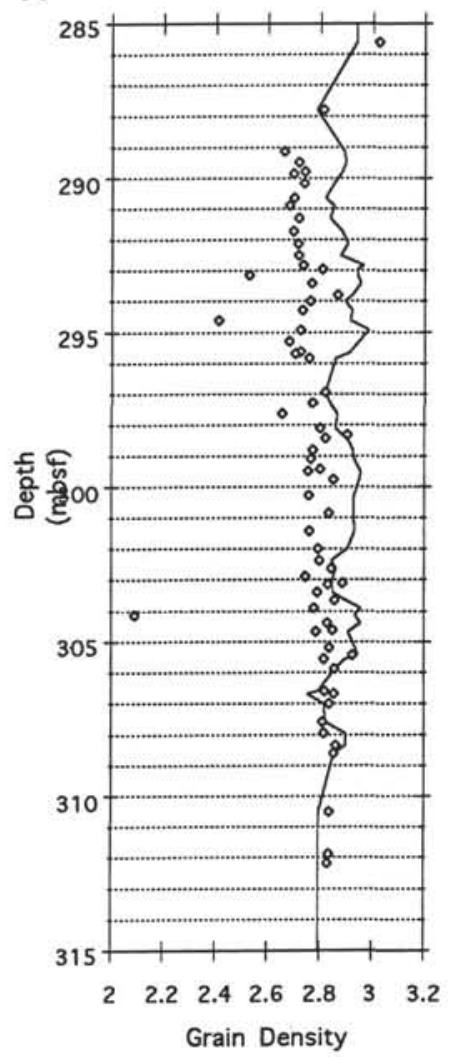

$\left(\mathrm{g} / \mathrm{cm}^{3}\right)$
B

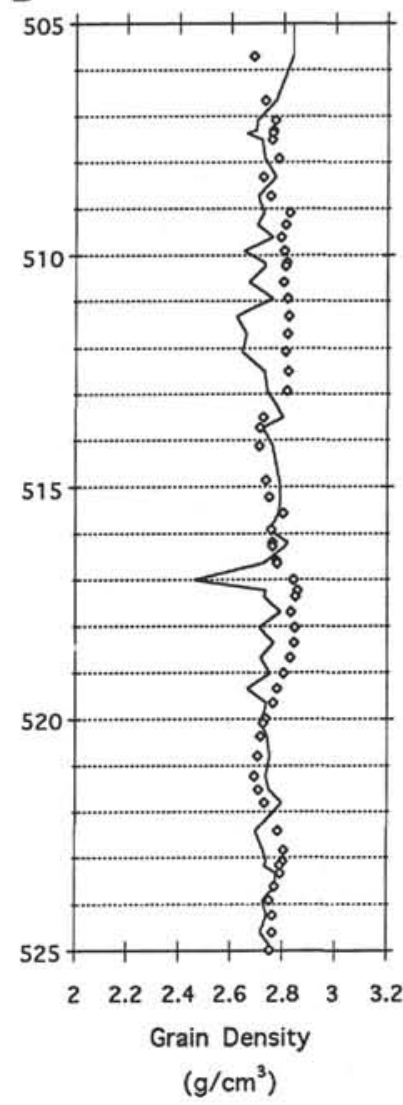

Figure 15. Depth plot of core and model grain density. Core measured densities (diamonds) do not closely match predicted densities calculated from inversion modeling results (solid line). A. Hole 904A. B. Hole 906A.

ments above and below. The calcitic and clay volumes, however, increase dramatically at the boundary (Fig. 9).

The compositions of sequence boundaries are well illustrated by the modeling results (Fig. 9) and are quite surprising. Sequence boundaries ol through $\mathrm{m} 4$, except $\mathrm{m} 5.2$, are associated with decreases in terrigenous components. This decrease is contrary to previously defined common characteristics of type-1 sequence boundaries (cf. Van Wagoner et al., 1988) and confirms the earlier observations of Mountain and Miller (1994). The lower sequence boundaries, except $\mathrm{m} 5$, are also associated with sharp drops in clay. Sequence boundaries $\mathrm{m} 3$ and $\mathrm{ml}$ are dissimilar from the underlying boundaries. Although they are still associated with lower clay components, they are directly overlain by units with increased terrigenous components.

\section{Site 903}

Lithologies from inversion of logs from Holes 903A and 903C were used to characterize the composition of upper slope Site 903. Log data covered middle Miocene through middle Pleistocene sediments. Modeling results are presented in Figures 10 and 11.

Log data were of poor quality in Hole $903 \mathrm{C}$, and only spotty modeling results are available (Fig. 11). The interval between the $\mathrm{m} 1.5$ and $\mathrm{m} 2$ upper Miocene sequence boundaries is the only lengthy inter$\mathrm{val}$ in Hole $903 \mathrm{C}$ where high-quality inversion modeling results were obtained. Overall results from this interval are very similar to those from the same stratigraphic interval in Hole 902D.

Log data from Hole 903A are quite good and provide nearly complete inversion modeling results to characterize the uppermost Mio- 
cene to upper Pleistocene sediments at this site (Fig. 10). Upper Miocene lithologic character is again similar to the upper Miocene section at Site 902 although lower overall porosities allow for larger apparent fractions of the lithotype end-members.

Compositional properties of the Pleistocene section are dramatically different from the underlying Miocene sediments. Terrigenous components are an average $9 \%$ higher in the Pleistocene than those in the underlying Miocene sediments. The percentage of clay is also higher, continuing a trend that begins in the middle Miocene. The clay fraction also exhibits clear cyclical variations in units that range from 10 to $45 \mathrm{~m}$ in thickness.

Site 903 contains many intervals with incomplete core recovery. Poor recovery resulted from extensive flow-in in the advanced piston coring (APC) intervals, loss of sandy? intervals in extended coring barrel (XCB) cores, and overall poor recovery throughout the intervals drilled with the rotary coring barrel (RCB). Although inversion modeling results provide lithologic estimates for most of the APC and many XCB intervals, the strata drilled by the RCB method had terrible hole conditions, which limited the applicability of the inversion modeling technique. Inversion modeling results in APC coring intervals show no consistent lithologic differences between flow-in and recovered sections (see Fig. 10, Cores 150-903A-8H through $20 \mathrm{H}$ ): flow-in is apparently not caused by a specific lithology.

Site 903 provides an opportunity to contrast compositions of Pleistocene sequence boundaries, created during times of glacioeustatic dominance, and older sequence boundaries created under with less well-defined forcing conditions. Increased terrigenous components occur just above Pleistocene-age sequence boundaries, which is similar to upper Miocene sequence boundaries. Boundary $\mathrm{p} 4$, however, is more similar to lower Miocene sequence boundaries exhibiting reduced terrigenous material. Clay components in the sediments immediately above sequence boundaries, unlike their Miocene counterparts, are split equally among increasing and decreasing trends. This may be a function of increased detrital clay in the sediments just above Pleistocene sequence boundaries as noted by shipboard sedimentologists (Mountain, Miller, Blum, et al., 1994, see individual site chapters).

\section{Site 904}

Site 904 (see Fig. 12) is in a slope position similar to Site 902; however, the Miocene section is much thinner, which allows for superb recovery and characterization of the Oligocene and Eocene intervals. Hole $904 \mathrm{~A}$, the only hole at this site, provided very good log and core data. Therefore, the main benefit of modeling this hole was the elimination of sampling bias in sedimentary petrography analyses and comparison of results to Site 902 .

Middle and upper Eocene chalks in Hole 904A have low, uniform terrigenous and opaline percentages. Calcareous and clay components are variable and in a reciprocal relationship. Middle Eocene chalks average $28 \%$ calcite and $1 \%$ clay; however, the overlying upper Eocene chalks have $20 \%$ calcite and $13 \%$ clay on average. The change at the middle to upper Eocene boundary is very abrupt. Cycles in the percentages of each of these minerals are apparent in both middle and upper Eocene intervals and range from 5 to $15 \mathrm{~m}$ in thickness.

Oligocene sediments at this site are similar in composition to those at Site 902. The lowermost bed of the Oligocene is rich in terrigenous and clay, presumably from the incorporation of detrital glauconite into the detrital terrigenous sediments (cf. Mountain, Miller, Blum, et al., 1994, see "Site 904" chapter). Compositional variation of terrigenous and calcareous components at 314 and 327 mbsf in Hole 904A suggest the possible further sequence stratigraphic division of Oligocene-aged sediments. Compositional variations at these depths are similar to those found at $271 \mathrm{mbsf}$ where boundary m5.2 is located and thus warrant this suggestion.

Although absolute weight fractions vary, the overall composition of the Miocene section at Site 904 is quite similar to Site 902. Site 904 has similar trends in decreasing terrigenous and calcareous frac- tions along with increasing clay just below the $\mathrm{m} 3$ middle Miocene boundary.

The composition of sediments around sequence boundaries at Site 904 differs from those at Site 902 . For example, sequence boundary $\mathrm{ol}$ is dramatically different in Sites 902 and 904. At Site 902, the boundary has sediments high in terrigenous minerals below the boundary; at Site 904, the only sediments with high terrigenous content are above the sequence boundary. Sequence boundary $\mathrm{m} 5.2$ is also different at Site 904 than it is at Site 902. In Hole 904A, the boundary conforms with other lower and middle Miocene boundaries and exhibits decreasing terrigenous and clay components. Hole 902D, on the other hand, shows no decrease in terrigenous sediments across the $m 5.2$ boundary.

Results from Hole 904A show that sequential sequence boundaries consist of variable compositions. Examples are as follows:

1. Boundary e2 is apparently caused by an increase in opaline (opal-CT) content.

2. Boundary el is caused by a decrease in calcareous material and concomitant increase in clay.

3. Boundary ol results from an increase in terrigenous and clay end-members along with a decrease in calcite.

4. Boundary $m 6$ results from decreases in terrigenous and clay percentages and an increase in calcite.

5. Boundary $\mathrm{m} 3$ results from a decrease in terrigenous and clay end-members.

The last example should be held with some reservation because large sums of negative errors persist throughout the $\mathrm{m} 4$ sequence.

\section{Site 905}

Modeling results from Hole 905A, the only hole at Site 905, are not presented. The caliper log, while measuring hole diameters no greater than 16 in. $(40.64 \mathrm{~cm})$, appears to be measuring at its upper limit of detection. Although the hole diameter is 3 in. $(7.62 \mathrm{~cm})$ smaller than the caliper's normal operating maximum, the uniform, flat-topped nature of the curve is a strong indicator that the caliper arm is opened to its fullest extent. This implies the tool was malfunctioning and as such, compositional model input data and results are all probably incorrect.

\section{Site 906}

Site 906 is another mid-slope site. This site is different from the other mid-slope sites in that it was drilled through the seismic expression of a Miocene slope canyon. Log and core data from Hole 906A are of overall excellent quality. Modeling was performed mainly for comparison to other sites, and to characterize the composition of the main canyon fill interval where core recovery was very poor. Modeling results are presented in Figure 13.

Nearly all stratigraphic intervals, ranging from Eocene to upper Miocene, have compositional properties and trends strikingly similar to those at Site 902.

Modeling results greatly increase our knowledge of the composition of the sediments filling the Miocene slope canyon. The fill interval, ranging from Core $150-906 \mathrm{~A}-45 \mathrm{X}$ to $41 \mathrm{X}$, had less than $25 \%$ recovery. Modeling results indicate the fill consists of $65 \mathrm{~m}$ of sediments having a clay content that increases upward; this sediment has a generally low and uniform terrigenous component. The section consists of four cycles, each about $15 \mathrm{~m}$ thick, having clay contents that increases upward. Additionally, the canyon-fill contains some of the highest concentrations of "heavy" lithotypes of any interval penetrated during Leg 150. Calcite and opaline concentrations are also surprisingly high (up to $25 \mathrm{wt} \%$ ), considering that the fill is in the middle Miocene siliciclastic succession. 
Most sequence boundaries have similar compositions to those at Site 902 . An additional boundary, can2, results from a dramatic drop in clay volume and increases in the other lithotypes. Canl was poorly characterized by log inversion because of a washout in the hole immediately above the boundary.

\section{DISCUSSION AND SUMMARY}

Log inversion modeling results accurately portray lithologic characteristics of logged intervals from Sites 902, 903, 904, and 906. They provide semiquantitative estimates of five lithotype end-members that carry important sedimentary information about thin stratigraphic units, sequence and sequence boundary characteristics, and compositional information about intervals with incomplete core recovery.

Results are, however, less than ideal. The accuracy of modeling results has limitations due to (1) the inability to incorporate all minerals into the model, (2) the use of data from only three limited intervals in Holes 904A and 906A, (3) the lack of application of rebound corrections to core porosities, and (4) several other problems cited earlier, which are of relatively minor importance. I must stress, however, that these results are accurate insofar as they can be verified with available independent and internal checks; they probably represent the end-member lithologies to within $10 \mathrm{wt} \%$. Thus, the results provide valuable high-resolution compositional information for all intervals with valid logging data, and they therefore improve the lithologic characterization of sequences cored and logged during Leg 150.

Many of the characteristics and trends noted in this study could be partially replicated by sedimentary petrography. Petrographic studies, however, contain two shortcomings that this log inversion modeling rectifies. The first is that petrographic analyses are not possible where core recovery is incomplete. The second is that significant time is required for petrographic analyses, and high-resolution studies are thus inhibited. Log inversion results dramatically improve the sampling increment of lithologic estimates, and they do not depend upon core recovery. While it is true that log inversion modeling is unable to identify all the minerals observed by petrographic analyses, modeling results indicate the lithotypes used for this study contain stratigraphic information of equal value to that obtained from petrographic analyses.

One the most significant results of the high-resolution lithologic $\mathrm{i}_{\mathrm{i}}$ version modeling is the recognition of lithologic cycles ranging from 5 to $65 \mathrm{~m}$ in thickness. Specific examples of well-developed cyclicity include the variable clay intervals in Holes 904A (310-420 mbsf; Fig. 12) and 906A (360-420 mbsf; Fig. 13. Although it is beyond the scope of this paper to estimate the periodicity of these cycles, a quick evaluation is warranted to see if they may carry significant information about the influence of glacioeustatic or tectonic forces on sequence development. I begin this thought-experiment by first noting that the clay cycles are constrained by sequence boundaries el and ol (Fig. 12). Biostratigraphy indicates these surfaces lie between nannofossil Zones NP18 and NP19/NP20 (Mountain, Miller, Blum, et al., 1994, see "Site 904" chapter). Using the time scale of Berggren et al. (1985), the maximum estimated time increment between the $\mathrm{e} 1$ and ol surfaces is approximately $3.25 \mathrm{~m} . \mathrm{y}$. Thus, the six clay cycles average about 0.5 m.y per cycle. Using the minimum estimated biostratigraphic time interval (approximately 1.15 m.y.) lowers the estimated periodicity to about $0.2 \mathrm{~m}$.y. per cycle. While these estimates obviously need refinement, it is immediately clear that the periodicity of these upper Eocene lithologic cycles is far shorter than that usually attributed to tectonic forcings (Vail et al., 1977). This in turn tends to support Poag's (1987) assertion that upper Eocene sediment dispersion on the New Jersey Margin was strongly influenced by glacioeustatic forces.
Lithologies of sequences and sequence boundaries were more completely characterized by these modeling results through extended coverage and decreased sampling interval. The results thus provide better inter-site correlation and lithologic characterization. For example, results indicate that while many similarly aged lithologic units from different sites contain similar compositions, trends are often quite dissimilar. Specifically, while upper Eocene sediments at midslope Sites 902, 904, and 906 (Figs. 9, 12, 13) all contain generally low terrigenous contents, substantially higher terrigenous contents appear in the uppermost $5 \mathrm{~m}$ at Sites 902 and 906, which are not matched at Site 904. Whether this difference indicates increased erosion by overlying Oligocene sands or heterogeneous deposition during the latest Eocene is unknown; however, the results are surprising in light of seismic stratigraphic studies by Poag and Mountain (1987) and Schlee and Hinz (1987), which suggest uniform bedding and homogenous lithologic compositions on the upper slope. Log inversion modeling thus indicates that the upper and middle slopes are a dynamic system and that a layer-cake model of sedimentation is not applicable.

Characterization of sequence development on the New Jersey Margin, one of the primary goals of Leg 150 , clearly requires a more regional perspective than can be provided by Leg 150 data alone. Drilling on the New Jersey coastal plain (cf. Miller et al., 1994) has provided important additional information concerning coeval strandline to nearshore sediments. Thus, only data from the shelf and rise are still needed to complete the characterization. The accuracy with which this method predicts lithology, combined with its applicability to commonly acquired downhole logging data, indicate it could play a significant role in furthering our understanding of sequence development on the New Jersey Margin. Application of this methodology to coastal plain sites and previously drilled exploration wells on the continental shelf may provide valuable additional information much as it did for the sites studied in this paper. Most importantly, the application of this methodology to commercial wells and future ODP sites on the shelf (see Fig. 1) could provide a valuable three-dimensional view of lithologic variation within sequences on the New Jersey Margin.

\section{ACKNOWLEDGMENTS}

I thank R.M. Ostermeier for teaching me the principles and applications of consistent core-log integration in log inversion modeling. I also wish to express my sincerest thanks to Peter Blum for facilitating the use of laboratory equipment at ODP, College Station, and to J. Coombs for preparing and processing the XRD samples. J.M. Lorenzo and G.S. Mountain provided valuable information on sequence boundary locations. Finally, I wish to express my deep gratitude to J. Revenaugh and R. Garrison for their help in developing an earlier version of the manuscript, and to J.H. Doveton and R.F. Wendlandt for their thorough and thoughtful reviews. This research was supported by ODP Grant No. 150-20783A.

\section{REFERENCES}

Bayliss, P., 1986. Quantitative analysis of sedimentary minerals by powder X-ray diffraction. Powd. Diffr., 1:37-39.

Berggren, W.A., Kent, D.V., Flynn, J.J., and Van Couvering, J.A., 1985. Cenozoic geochronology. Geol. Soc. Am. Bull., 96:1407-1418.

Bish, D.L., and Reynolds, R.C., Jr., 1989. Sample preparation for X-ray diffraction. Rev. Mineral., 20:73-100.

Chung, F.H., 1974a. Quantitative interpretation of X-ray diffraction patterns, I. Matrix-flushing method of quantitative multicomponent analysis. $J$. Appl. Cryst., 7:519-525.

1974b. Quantitative interpretation of X-ray diffraction patterns, II. Adiabatic principle of X-ray diffraction analysis of mixtures. J. Appl. Cryst., 7:526-531. 
Doveton, J.H., 1986. Log Analysis of Subsurface Geology: Concepts and Computer Methods: New York (Wiley).

Fisher, A.T., Abrams, L., and Busch, W.H., 1992. Comparison of laboratory and logging data from Leg 129 and the inversion of logs to determine lithology. In Larson, R.L., Lancelot, Y., et al., Proc. ODP, Sci. Results, 129: College Station, TX (Ocean Drilling Program), 507-527.

Gearhart Industries Inc., 1978. Formation Evaluation Data Handbook: Fort Worth, TX (Gearhart Industries).

Greenlee, S.M., and Moore T.C., 1988. Recognition and interpretation of depositional sequences and calculations of sea level changes from stratigraphic data-offshore New Jersey and Alabama Tertiary. In Wilgus, C.K., et al. (Eds.), Sea-level Changes-An Integrated Approach. Spec. Publ.-Soc. Econ. Paleontol. Mineral., 42:329-356.

Hamilton, E.L., 1971. Prediction of in-situ acoustic and elastic properties of marine sediments. Geophysics, 36:266-284.

Hanawalt, J.D., 1983. History of the powder diffraction file in crystallography in North America-apparatus and methods. Am. Cryst. Assoc., 215219.

Harvey, P.K., Bristow, J.F., and Lovell, M.A., 1990. Mineral transforms and downhole geochemical measurements. Sci. Drill., 1:163-176.

Hertzog, R.C., Colson, J.L., Seeman, B., O'Brien, M.S., Scott, H.D., McKeon, D.C., Wraight, P.D., Grau, J.A., Ellis, D.V., Schweitzer, J.S., and Herron, M.M., 1989. Geochemical logging with spectrometry tools. SPE Form. Eval., 4:153-162.

Mattick, R.E., and Libby-French, J., 1988. Petroleum geology of the United States Atlantic continental margin. In Sheridan, R.E., and Grow, J.A. (Eds.), The Geology of North America (Vol. I-2): The Atlantic Continental Margin, U.S. Geol. Soc. Am., 445-462.

Miller, K.G., et al., 1994. Proc. ODP, Init. Repts., 150X: College Station, TX (Ocean Drilling Program).

Mountain, G.S., and Miller., K.G., 1994. Identifying the origin and age of sequence boundaries on the New Jersey slope: ODP Leg 150. Geol. Soc. Am. Abstr. Programs, A-90.

Mountain, G.S., Miller, K.G., and Blum, P., 1993. Ocean Drilling Program Leg 150 Scientific Prospectus-the New Jersey Continental Slope and Rise. ODP Sci. Prospectus 50: College Station, TX (Ocean Drilling Program).

Mountain, G.S., Miller, K.G., Blum, P., et al., 1994. Proc. ODP, Init. Repts., 150: College Station, TX (Ocean Drilling Program).

Mountain, G.S., Miller, K.G., and Christie-Blick, N., 1992. Upper Paleogene to Neogene depositional sequences on the U.S. Middle Atlantic Margin: the Mid-Atlantic Transect. ODP Drilling Proposal 348: College Station, TX (Ocean Drilling Program).

Poag, C.W., 1987. The New Jersey Transect: stratigraphic framework and depositional history of a sediment-rich passive margin. In Poag, C.W., Watts, A.B., et al., Init. Repts. DSDP, 95: Washington (U.S. Govt. Printing Office), 763-817.
Poag, C.W., and Mountain, G.S., 1987. Late Cretaceous and Cenozoic evolution of the New Jersey continental slope and upper rise: an integration of borehole data with seismic reflection profiles. In Poag, C.W., Watts, A.B., et al., Init. Repts. DSDP, 95: Washington (U.S. Govt. Printing Office), 673-724.

Quirein, J., Kimminau, S., LaVigne, J., Singer, J., and Wendel, F., 1986. A coherent framework for developing and applying multiple formation evaluation models. Trans. SPWLA 27th Annu. Logging Symp., 27:DD1DD17.

Savre, W.C., 1963. Determination of a more accurate porosity and mineral composition in complex lithologies with the use of the sonic, neutron and density surveys. J. Pet. Tech., 15:945-959.

Schlee, J.S., and Hinz, K., 1987. Seismic stratigraphy an facies of continental slope and rise seaward of Baltimore Canyon Trough. AAPG Bull., 71:1046-1067.

Schlumberger Well Services, 1987a. Log Interpretation Principles/Applications: Houston (Schlumberger).

, 1987b. Log Interpretation Charts: Houston (Schlumberger).

Schmoker, J.W., and Hester, T.C., 1983. Organic carbon in Bakken Formation, United States portion of the Williston Basin. AAPG Bull., 67:21652174.

Schwalbach, J.R., and Bohacs, K.M., 1992. Field investigation techniques for analysis of the Monterey Formation. In Schwalbach, J.R., and Bohacs, K.M. (Eds.), Sequence Stratigraphy in Fine-grained Rocks: Examples from the Monterey Formation. Spec. Publ.-Soc. Econ. Paleontol. Mineral., 70:7-21.

Serra, O., Baldwin, J.L., and Quirein, J.A., 1980. Theory, interpretation and practical applications of natural gamma ray spectroscopy. Trans. SPWLA 21st Annu. Logging Symp., 27:Q1-Q30.

Vail, P.R., Mitchum, R.M., and Thompson, S., III, 1977. Global cycles of relative changes in sea level. In Payton, C.E. (Ed.), Seismic Stratigraphy: Applications to Hydrocarbon Exploration. AAPG Mem., 26:83-97.

Van Wagoner, J.C., Posamentier, H.W., Mitchum, R.M., Jr., Vail, P.R., Sarg, J.F., Loutit, T.S., and Hardenbol, J., 1988. An overview of the fundamentals of sequence stratigraphy and key definitions. In Wilgus, C.K., Hastings, B.S., Ross, C.A., Posamentier, H.W., Van Wagoner, J., and Kendall, C.G.St.C. (Eds.), Sea-Level Changes: An Integrated Approach. Spec. Publ.-Soc. Econ. Paleontol. Mineral., 42:39-45.

Wendlandt, R.F., and Bhuyan, K., 1990. Estimation of mineralogy and lithology from geochemical log measurements. AAPG Bull., 76:837-856.

Date of initial receipt: 17 February 1995

Date of acceptance: 29 August 1995

Ms 150SR-030 